\title{
Mitochondrial UCP4 Mediates an Adaptive Shift in Energy Metabolism and Increases the Resistance of Neurons to Metabolic and Oxidative Stress
}

\section{Dong Liu, ${ }^{+1}$ Sic. L. Chan, ${ }^{+1}{ }^{1}$ Nadja C. de Souza-Pinto, ${ }^{2}$ John R. Slevin, Jr., ${ }^{1}$ Robert P. Wersto, ${ }^{3}$ Ming Zhan, ${ }^{3}$ Khadija Mustafa, ${ }^{1}$ Rafael de Cabo, ${ }^{4}$ and Mark P. Mattson*,1,5}

${ }^{1}$ Laboratory of Neurosciences; ${ }^{2}$ Laboratory of Molecular Gerontology; ${ }^{3}$ Research Resources Branch;

${ }^{4}$ Laboratory of Experimental Gerontology, National Institute on Aging Intramural Research Program, Baltimore, MD; ${ }^{5}$ Department of Neuroscience, Johns Hopkins University School of Medicine, Baltimore, MD

Received December 17, 2005; Revised February 21, 2006; Accepted February 23, 2006

\begin{abstract}
The high-metabolic demand of neurons and their reliance on glucose as an energy source places them at risk for dysfunction and death under conditions of metabolic and oxidative stress. Uncoupling proteins (UCPs) are mitochondrial inner membrane proteins implicated in the regulation of mitochondrial membrane potential $\left(\Delta \psi_{\mathrm{m}}\right)$ and cellular energy metabolism. The authors cloned UCP4 cDNA from mouse and rat brain, and demonstrate that UCP4 mRNA is expressed abundantly in brain and at particularly high levels in populations of neurons believed to have high-energy requirements. Neural cells with increased levels of UCP4 exhibit decreased $\Delta \psi_{\mathrm{m}}$ reduced reactive oxygen species (ROS) production and decreased mitochondrial calcium accumulation. UCP4 expressing cells also exhibited changes of oxygen-consumption rate, GDP sensitivity, and response of $\Delta \psi_{\mathrm{m}}$ to oligomycin that were consistent with mitochondrial uncoupling. UCP4 modulates neuronal energy metabolism by increasing glucose uptake and shifting the mode of ATP production from mitochondrial respiration to glycolysis, thereby maintaining cellular ATP levels. The UCP4-mediated shift in energy metabolism reduces ROS production and increases the resistance of neurons to oxidative and mitochondrial stress. Knockdown of UCP4 expression by RNA interference in primary hippocampal neurons results in mitochondrial calcium overload and cell death. UCP4-mRNA expression is increased in neurons exposed to cold temperatures and in brain cells of rats maintained on caloric restriction, suggesting a role for UCP4 in the previously reported antiageing and neuroprotective effects of caloric restriction. By shifting energy metabolism to reduce ROS production and cellular reliance on mitochondrial respiration, UCP4 can protect neurons against oxidative stress and calcium overload.
\end{abstract}

doi: 10.1385/NMM:8:3:389

*Author to whom all correspondence and reprint requests should be addressed. E-mail: mattsonm@grc.nia.nih.gov

${ }^{+}$These authors made equal contributions to this research. 
Index Entries: Caloric restriction; glucose transport; hippocampus; neuronal death; oxygen consumption.

\section{Introduction}

To support their high levels of electrochemical activity neurons produce large amounts of adenosine triphosphate (ATP) during mitochondrial oxidative phosphorylation and correspondingly large amounts of reactive oxygen species (ROS) (Mattson and Liu, 2002). This high-metabolic load on mitochondria places neurons at risk for energy failure, oxidative damage, and cell death during conditions of injury or disease (Beal, 1998; Hou and MacManus, 2002; Mattson and Kroemer, 2003). In addition, mitochondria play important roles in regulating cellular $\mathrm{Ca}^{2+}$ homeostasis in neurons in response to changes in synaptic activity (Simpson, 2000; Yang et al., 2003) and in pathological conditions such as stroke or exposure to neurotoxins (Kristián and Siesjö, 1998; Nicholls and Budd, 1998; Nasr et al., 2003). Moreover, mitochondrial ROS production and $\mathrm{Ca}^{2+}$ overload are often pivotal events in a form of physiological programmed-cell death called apoptosis (Deshmukh and Johnson, 1997). Elucidating the molecular mechanisms that control mitochondrial energy and ROS production, is therefore of considerable importance for understanding how neurons either adapt or succumb to metabolic and oxidative loads.

Uncoupling proteins (UCP) $1-5$ belong to a family of mitochondrial ion carriers located in the inner mitochondrial membrane (Pecqueur et al., 2001; Argiles et al., 2002). Among mammalian UCPs, UCP4 is highly conserved with homologs in plants, insects, and fish (Hănak and Jezek, 2001; Sokolova and Sokolov, 2005). UCPs share structural similarities with the adenine nucleotide translocator (Vianello et al., 1994), the aspartate/glutamate antiporter (Samartsev et al., 1997), the oxoglutarate/malate carrier (Yu et al., 2001), and the dicarboxylate carrier (Wieckowski and Wojtczak, 1997) with three putative mitochondrial energy transfer motifs and predicted six transmembrane domains. These mitochondrial transporters can participate in proton transfer across the membrane, although not all the mitochondrial carrier proteins might have a native uncoupling function (Roussel et al., 2002). The facilitated protonphoric action of UCPs results in reduced mitochondrial membrane poten- tial $\left(\Delta \psi_{\mathrm{m}}\right)$ and ROS production (Negre-Salvayre et al., 1997; Arsenijevic et al., 2000). Even "mild" uncoupling will significantly reduce mitochondrial ROS production (Korshunov et al, 1997; Starkov, 1997; Miwa and Brand, 2003). The uncoupling activity of UCPs can also be activated by oxidative stress (Echtay et al., 2002, 2003) and free-fatty acids (Hagen and Lowell, 2000), or inhibited by purine nucleotides such as guanosine diphosphate (GDP) (Nicholls and Locke, 1984). However, in many cell types, it is likely that the fatty acid-induced response is mediated by more than one mitochondrial carrier protein, including the adenine nucleotide translocator, the dicarboxylate carrier (Andreyev et al, 1989; Wieckowski Wojtczak, 1997; Korshunov et al., 1998) rather than UCPs alone. UCP1 is expressed in brown adipose cells in which it is upregulated by cold temperature resulting in the production of heat (Pecqueur et al., 2001; Argiles et al., 2002). UCP2 is widely expressed in multiple tissues including certain regions of brain, whereas UCP3 is expressed principally in skeletal muscle cells (Dulloo et al., 2001). UCP4 and UCP5 brain mitochondrial carrier protein 1 (BMCP1) are expressed mainly in the nervous system (Sanchis et al., 1998; Mao et al., 1999) in which there are three isoforms of human UCP5 (Yu et al., 2000; Yang et al., 2002) and UCP5 might regulate respiration and ROS production (KimHan et al., 2001). UCP4 mRNA transcripts are exclusively expressed in brain tissues (Mao et al., 1999) and are more robustly expressed in rodent brain than BMCP1/UCP5 (Andrews et al., 2005). The function(s) of UCP4 in the nervous system is unknown. Although it is believed that UCPs mediate adaptive responses of cells and the organism to environmental perturbations, this has only been clearly established in the case of UCP1 which is upregulated in brown fat cells in response to cold resulting in mitochondrial uncoupling and heat production (Erlanson-Albertsson, 2003). Transgenic mice expressing UCP1 in skeletal muscle exhibit a higher metabolic rate and increased glucose transport (Li et al., 2000; Han et al., 2003), suggesting that cells might compensate for reduced ATP production from mitochondrial respiration. Additional evidence that UCPs are involved in the regulation of 
energy metabolism and ROS production include: studies of transgenic mice and cultured pancreatic $\beta$ cells have shown that UCP2 negatively regulates insulin secretion and might play an important role in the development of diabetes (Chan et al., 1999; Zhang et al., 2001); UCP3 stimulates glucose transport and GLUT4 translocation by activation of the phosphoinositide3-kinase-dependent pathway in muscle cells (Huppertz et al., 2001); fasting increases the expression of UCP2 and UCP3 (Boss et al., 1997; Millet et al., 1997); and macrophages isolated from UCP2-/-mice and skeletal muscle mitochondria isolated from UCP3-/- mice show increased ROS production (Arsenijevic etal., 2000; Vidal-Puig etal.,2000). Recent findings suggest roles for UCP2 and UCP3 in protecting neurons against metabolic and oxidative insults (Mattiasson et al., 2003; Vincent et al., 2004).

Inlight of theimportant roles of other UCPs in physiological and pathophysiological processes in nonneural tissues, the authors cloned UCP4 from mouse and rat brain, and characterized its regional and cellular expression in the brain. The authors showed that UCP4 is highly enriched in neurons in which it regulates energy and oxyradical metabolism in ways that allow the neurons to adapt to stressful conditions.

\section{Materials and Methods}

\section{Cloning of UCP4 cDNA From Rodent Brain}

Total RNA was extracted from different regions of rat and mouse brain. Primer pairs and probes were designed and synthesized based on published rat and human UCP4 sequences (Genebank Accession numbers AJ300164 and AF110532, respectively). Primers for mouse UCP4 were forward primer, $5^{\prime}$ GCC AAT AAC ACC AGC CAT C $-3^{\prime}$ and reverse primer, 5'- GAG CGA GCA AAT TCC TAC -3'. Primers for rat UCP4 were: forward primer: $5^{\prime}$-TCC TTC CCT GAC CTC TCT TG-3' and reverse primer: 5'-TCT CCAAAGCAC TACAAAGTC-3'. The polymerase chain reaction (PCR) conditions used were $94^{\circ} \mathrm{C}$ for $1 \mathrm{~min}$ and 26 cycles of $94^{\circ} \mathrm{C}$ for $30 \mathrm{~s}, 55^{\circ} \mathrm{C}$ for $1 \mathrm{~min}$ and $68^{\circ} \mathrm{C}$ for $1 \mathrm{~min}$. UCP $4 \mathrm{cDNA}$ fragments (about 400-bp) were obtained by reverse transcriptase (RT)-PCR with RNA extracted from hippocampus, cortex, striatum, and midbrain of rat and mouse brains with SuperScript ${ }^{\mathrm{TM}}$ First-strand Synthesis System (Gibco, BRL). The cDNA fragments of UCP4 were cloned and subcloned into the pGEM- 42 vector
(Promega, San Luis Obispo, CA) to make riboprobes. Automated DNA sequencing confirmed that the cloned cDNA segments contained the UCP4 coding region with conserved mitochondrial energy transfer protein domains (Fig. 1). Subsequent to our cloning of mouse UCP4, another laboratory deposited the mouse UCP4 sequence in the Genebank database (AB106932).

\section{In Situ Hybridization}

In situ hybridization analysis was performed with ${ }^{35} \mathrm{~S}$-labeled riboprobes in rodent-brain tissue sections. Cryosections $(16 \mu \mathrm{m})$ were thaw-mounted onto charged slides, and were fixed in $4 \%$ paraformaldehyde in phosphate-buffered saline (PBS), dehydrated, diliapidated, and airdried. The hybridization solution contained $10^{7} \mathrm{cpm} / \mathrm{mL}$ riboprobe in hybridization buffer. The slides were coverslipped and placed in $5^{\circ} 5^{\circ} \mathrm{C}$ humidified incubator overnight. The slides were washed through graded salt solutions, dehydrated, and exposed to hyperfilm-max (Amersham Piscataway, NJ) for 2 wk. The slides were then dipped in emulsion and stored at $4^{\circ} \mathrm{C}$ for $3 \mathrm{wk}$. After developing and fixing, the slides were counterstained with thionin.

\section{Immunoblot Analyses}

For immunoblots, proteins (50 $\mu \mathrm{g} /$ lane) from different regions of rat brain were separated by electrophoresis in a $12 \%$ sodium dodecyl sulfate (SDS)-polyacrylamide gel, transferred to a nitrocellulose membrane, and incubated with the UCP4antibody (Research Diagnostics Inc., NJ, 1:1000). To confirm equal protein loading, the same blot was reprobed with a mouse antiactin antibody (Sigma, St. Louis, MO; 1:10,000 dilution). Horseradish peroxidase (HRP)-conjugated secondary antibodies were used in all Western blots (Vector Laboratories) and visualized by enhanced chemiluminescence (Amersham).

\section{Generation of Pheochromocytoma Cell Lines Stably Expressing hUCP4}

The recombinant plasmid encoding full-length human UCP4 (pcDNA-UCP4) was kindly provided by Pan (Genentech). Pheochromocytoma (PC12) cell lines overexpressing UCP4 were generated using expression plasmids and cell transfection and 

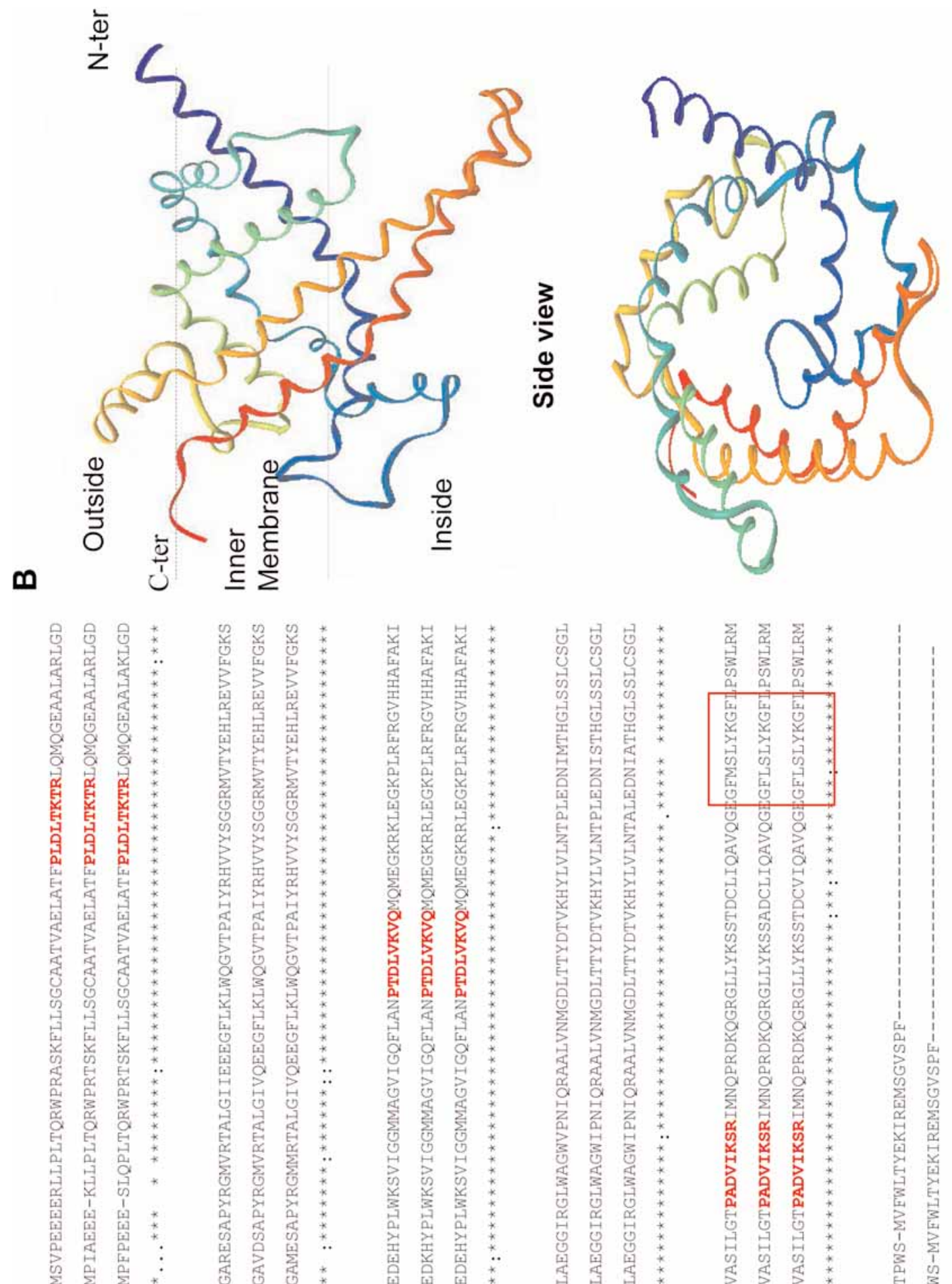

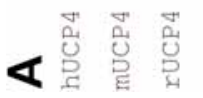
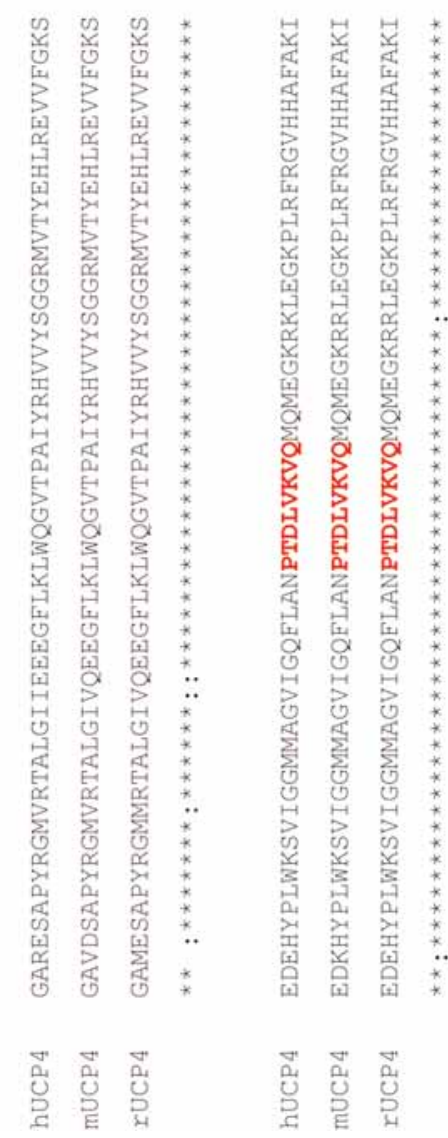

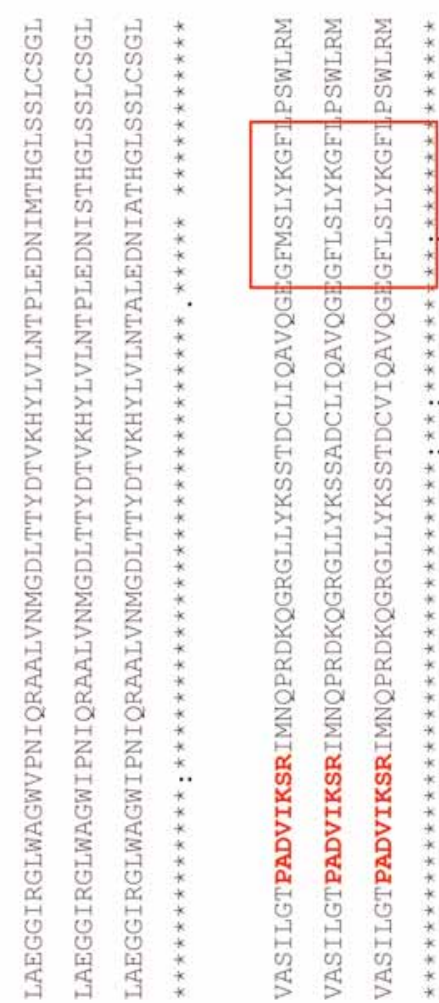

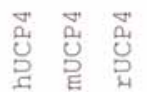

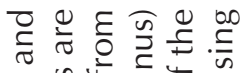

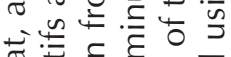

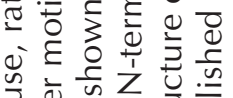

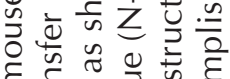

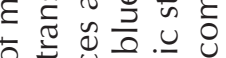

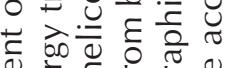

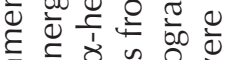

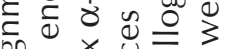

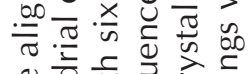

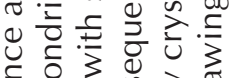
उ.

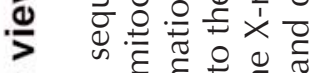

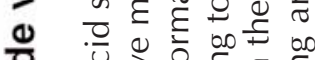
은

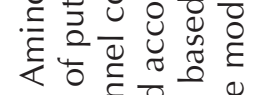

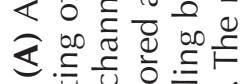

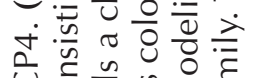
Uิ

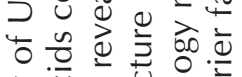
จ.

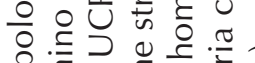

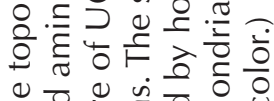

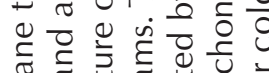

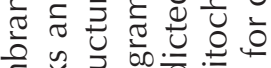

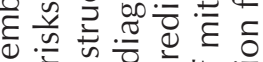
हैं

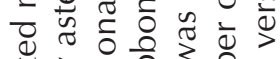

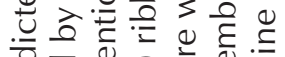

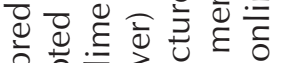

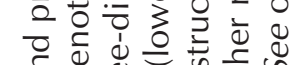

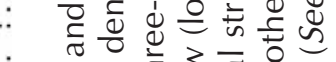

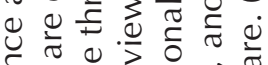
更

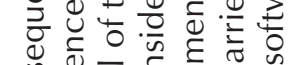

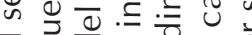
음

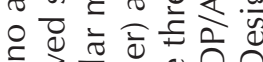

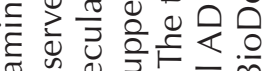
둥

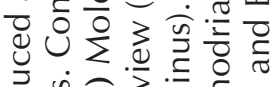

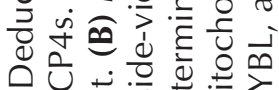

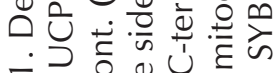

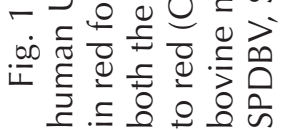


selection protocols described previously (Chan et al., 2004). Briefly, cells were grown in 35-mm dishes in RPMI medium supplemented with $10 \%$ horse and 5\% fetal-bovine sera until they reached $80 \%$ confluency. Transfection was carried out using Lipofectin reagent $(1 \mu \mathrm{g}$ DNA in $10 \mu \mathrm{L}$ of Lipofectin) according to the manufacturer's protocol (Invitrogen). Stable transfectants of PC12 cells were obtained after selection for growth in the presence of geneticin (500 mg/L). hUCP4 expression was confirmed by RT-PCR and immunoblot. Several clones of hUCP4 expressing cells were selected and maintained in the presence of geneticin $(250 \mathrm{mg} / \mathrm{L})$.

\section{Measurements of $\mathrm{O}_{2}$ Consumption and Time-Lapse Imaging of $\Delta \psi_{m}$}

The $\mathrm{O}_{2}$ consumption rates were measured using a thermo-jacketed Clark-type oxygen electrode with mini-stirring bar at $37^{\circ} \mathrm{C}$ in digitonin-permeabilized cells (Vercesi et al., 1991; Kowaltowski et al., 2002; Yang et al., 2002). Signals were collected through an amperometric box and recorded with a standard two-channel recorder. Cells were suspended in culture medium at a density of $1 \times 10^{7}$ cells $/ \mathrm{mL}$. After centrifugation, cells were resuspended in a HEPESbuffer containing $(\mathrm{mM}) 145 \mathrm{NaCl} ; 5 \mathrm{KCl} ; 1.8 \mathrm{CaCl}_{2}$; $0.8 \mathrm{MgCl}_{2} ; 10$ D-glucose; 10 HEPES; 5 succinate; and $0.3 \mathrm{ADP}$, with/without rotenone $(2 \mu \mathrm{M})(\mathrm{pH} 7.0$ and $295 \mathrm{mOsm}$ ) in an oxymetry chamber under constant stirring at $37^{\circ} \mathrm{C}$. Oxygen uptake was monitored after the addition of digitonin $(0.001 \%)$. The concentration of digitonin used was calibrated on tetramethylrhodamine ethyl ester (TMRE)-loaded cells and did not alter the $\Delta \psi_{\mathrm{m}}$ of cells. State 3 respiration rates were recorded in the presence of adenosine diphosphate (ADP) $(0.3 \mathrm{mM})$, and the ATP synthase inhibitor oligomycin $(2 \mu \mathrm{g} / \mathrm{mL})$ was added to measure State 4 respiration. The respirationcontrol ratio (RCR) was calculated as the ratio of state $3 /$ state 4 respiration rates. The data were represented as ng atom $\mathrm{O} / \mathrm{min} / 1 \times 10^{7}$ cells at $37^{\circ} \mathrm{C}$. The $\mathrm{O}_{2}$ consumption rates were also measured in medium with nicotinamide adenine dinucleotide (NADH)-linked substrates (mM: 250 sucrose; 5 malate; 5 pyruvate; 5 glutamate; 100 EGTA; 10 HEPES; and 0.1\% BSA, pH 7.2, (Kowaltowski et al., 2002; data not shown). Cell viability was $95-100 \%$ as assessed by trypan blue exclusion assay before and after the oxygen consumption assay.
Changes of $\Delta \psi_{\mathrm{m}}$ in UCP4 and vector-transfected (VT) cells were measured by time-lapse confocal imaging (Zeiss, 510). Cells were loaded with a low concentration of TMRE ( $25 \mathrm{nM})$ to avoid "quench mode" for $15-20$ min at $37^{\circ} \mathrm{C}$, washed with HEPESbuffered saline, and maintained in HEPES-buffered saline containing TMRE ( $25 \mathrm{nM}$ ) throughout the course of the experiment. Images of TMRE fluorescence were acquired every $10 \mathrm{~s}$. The $\Delta \psi_{\mathrm{m}}$ of UCP 4 and VT cells at state 4 respiration was determined by addition of oligomycin in the presence of ADP, succinate, and rotenone. The $\Delta \psi_{\mathrm{m}}$ of UCP4 and VT cells analyzed in the presence or absence of digitonin was compared. The average pixel intensity per cell was determined using the Zeiss software and values were expressed as mean and SD of relative intensity normalized to baseline from multiple cells. Data were analyzed from measurements of 60-90 cells in 7-11 independent experiments.

\section{Measurements of $\Delta \psi_{m}$, ROS Production and $\mathrm{Ca}^{2+}{ }_{m}$ Levels}

Fluorescent probes (Molecular Probes, Eugene,OR) were used to measure mitochondrial membrane potential (TMRE) and ROS (dichlorofluorescein diacetate, DCF; and dihydrorhodamine, DHR) and mitochondrial $\mathrm{Ca}^{2+}$ concentration (rhodamine-2L [Rhod-2]). Two methods, confocal microscopy and flow cytometry were used to quantify the intensity of cellular fluorescence emitted from each probe on excitation at probe-appropriate wavelengths. For confocal microscopy-based analysis, cells grown on glass cover slips were incubated with $50 \mathrm{nM}$ TMRE (20 min), $10 \mu M$ DHR (30 min), or $5 \mu M$ Rhod-2-acetoxymethyl ester (AM) (60 min). In the case of TMRE imaging, the medium was changed to HEPESbuffered saline (Krohn et al., 1999) containing $25 \mathrm{nM}$ TMRE and the cultures were equilibrated at room temperature prior imaging. Fluorescence images of cells were acquired using a Zeiss 510 confocal microscopeand average pixel intensity percell was obtained from an average of three to five culture dishes with 20-30 cells per dishes (Kruman and Mattson, 1999; Liu et al., 2002). For flow cytometric analysis, cells were harvested following brief incubation with $0.025 \%$ trypsin, pelleted by Low-speed centrifugation, and washed and diluted to a concentration of 1 $\times 10^{6}$ cells $/ \mathrm{mL}$ in RPMI 1640 medium. The suspended cells were labeled with TMRE (100nM), DHR $(10 \mu M)$ 
or Rhod-2 $(5 \mu M)$ as described previously, washed twice with fresh medium (maintained $50 \mathrm{nM}$ TMRE for $\Delta \psi_{\mathrm{m}}$ measurements) and then analyzed using a FACSscan (Becton-Dickson, San Jose, CA). Data were displayed as histograms of log fluorescence. The concentrations of TMRE used in the present study were similar to or lower than those used to measure mitochondrial membrane potential in previous studies (Krohn et al., 1999; Poppe et al., 2001; Liu et al., 2002).

\section{Measurements of Glucose Uptake, Cellular ATP and Lactate Levels}

For measurement of ATP concentrations cell lysates were analyzed using an ATP bioluminescence assay kit (Roche Diagnostics) and a luminometer (Optocomp II; MGM Instruments, Hamden, CT). Solutions of known ATP concentrations were used to generate a standard curve. Protein concentrations were determined with a BCA protein assay kit (Pierce, Rockford, IL) and ATP concentrations were expressed as nmoles/mg protein. For measurement of glucose uptake cells were washed three times with glucosefree medium and then incubated for $15 \mathrm{~min}$ in the presence of $1.5 \mu \mathrm{Ci} / \mathrm{mL}^{3} \mathrm{H}$-2-deoxyglucose at $37^{\circ} \mathrm{C}$. Phloretin, a selective inhibitor of glucose transport, was used to establish glucose transport-specific uptake of radiolabeled 2-deoxyglucose (Mark et al., 1997). The cells were then washed with fresh medium and lysed. An aliquot of the lysate was saved for protein assay and radioactivity in the remaining medium was counted using a scintillation counter. A lactate assay kit (Trinity Biotech, Berkeley Heights, NJ) was used for measurements of cellular lactate levels; solutions of known lactate concentration were used to generate a calibration curve. Cells were homogenized in PBS and the concentration of lactate in the homogenate was measured at an absorbance of 540 $\mathrm{nm}$; values were normalized to the protein concentration in the sample.

\section{Assesments of Apoptosis and Cell Survival}

PC12 cells were cultured onto $35 \mathrm{~mm}$ cell culture dishes in RPMI medium with G418 and then exposed to treatments. The cells were then fixed at selected time-points in $4 \%$ paraformaldehyde in PBS, and incubated with $10 \mu M$ Hoechst stain for $30 \mathrm{~min}$ and washed thrice in PBS. The Hoechst stained cells were kept in the dark and were examined using epifluorescence illumination (340 nm excitation). Cells with fragmented nuclear DNA were considered apoptotic, and the percentage of apoptotic cells in each culture was determined by counting three to four randomly chosen $\times 20$ microscope fields (counts were made in three to four culture dishes for each experimental condition).

Cell survival was evaluated with Alamarblue using methods similar to those described previously (White et al., 1996; O'Brien et al., 2000). Briefly, dissociated cells were counted and plated in 24-well plates $(1 \times$ $10^{6}$ cells/well) and exposed to treatments for $24 \mathrm{~h}$. The culture medium was removed and replaced with $300 \mu \mathrm{L} /$ well of $0.5 \%$ Alamar blue diluted in PBS, and incubated for $1-2 \mathrm{~h}$ at $37^{\circ} \mathrm{C}$ in a $5 \% \mathrm{CO}_{2}$ incubator. Levels of the Alamar blue reaction product were measured using a HTS 7000 Plus bioassay reader $(540 \mathrm{~nm}$ excitation and $590 \mathrm{~nm}$ emission wavelengths).

\section{Hippocampal Cell Cultures}

Procedures for preparation and maintenance of dissociated hippocampal cell cultures from embryonic rat (Sprague Dawley) embryos have been described previously (Mattson et al., 1995). Briefly, hippocampi were removed and subjected to mild trypsination and trituration. Dissociated neurons were seeded onto polyethylenimine-coated glass cover slips and maintained at $37^{\circ} \mathrm{C}$ in Neurobasal medium containing B-27 supplements, $2 \mathrm{mM}$ L-glutamine, $1 \mathrm{~m} M$ HEPES, and $0.001 \%$ gentamycin sulfate. All experiments were performed using 7-8 d old cultures. For cold exposure, cells were incubated at $4^{\circ} \mathrm{C}$ for increasing time periods up to $24 \mathrm{~h}$.

\section{UCP4 siRNA Preparation and Transfection}

UCP4 siRNA was synthesized by in vitro transcription (Silencer ${ }^{\mathrm{TM}}$ siRNA Construction Kit, Ambion) from oligo DNA templates. Briefly, several target oligonucleotide templates were designed along the rUCP4 coding region as well as a sequence in the $3^{\prime}$ untranslated region. All siRNAs were 21 nucleotides long with $3^{\prime}$ terminal noncomplementary dimers of uridine. Target sequences were compared to the Genebank database and any sequences present in other genes, including other members of the UCP family, were rejected. T7 primer with a leader sequence was used to synthesize antisense and sense RNA with T7 RNA polymerase. The leader sequence was removed and the resulting siRNA was purified, quantified, and labeled with fluorescein 
(Ambion). The siRNAs were transfected into cultured hippocampal neurons using oligifectamine (Ambion). A negative double-stranded RNA with scrambled sequence and GAPDH siRNA obtained from Ambion were transfected into cells as controls. Following siRNA transfection, UCP4 siRNA and GAPDH siRNA transfected cells were detected by confocal imaging with double or triple staining for UCP4, GADPH, and a neuronal marker (MAP2 or $\beta$-III tubulin). Total cell RNA was extracted from cultured hippocampal neurons at 24, 48 , and $72 \mathrm{~h}$ following transfection and semiquantitative RTPCR was performed. The PCR cycle was preselected and UCP4 PCR products were normalized to GADPH or actin PCR products obtained from the same cDNA preparation.

\section{Animals and Dietary Manipulation}

Male Fischer-344 rats were bred and reared in a vivarium at the NIA facility. They were housed individually in standard plastic cages with beta chip wood bedding. Control animals were fed a NIH-31 standard diet ad libitum. At 1 mo of age the calorie restricted animals were provided a vitamin and mineral fortified version of the same diet at a level of $40 \%$ less food (by weight) than ad libitum-fed rats consumed during the previous week. Filtered water was available ad libitum for all rats. The vivarium was maintained at a temperature of $25^{\circ} \mathrm{C}$, with relative humidity at $50 \%$ on a $12 / 12$-h light / dark cycle (lights on at 06:00). The calorie-restricted rats manifested decreased body temperature and plasma insulin levels, and increased free-fatty acids levels (data not shown) consistent with previous studies (Duffy et al., 1990; De Cabo et al., 2003). Rats were euthanized at $14 \mathrm{mo}$ of age between 09:00 and 11:00 after an overnight fast. All procedures were approved by the National Institute on Ageing Animal Care and use Committee and complied with National Institute Health guidelines for the care and use of laboratory animals.

\section{Statistics}

For single condition comparisons between control cells and cells with increased or decreased UCP4 levels, paired or unpaired Student's $t$-test was used. For multiple condition comparisons the data was subjected to ANOVA and pairwise comparisons were made using Scheffe posthoc tests.

\section{Results}

\section{Cloning and Structural Characterization of Mouse UCP4}

Total RNA was isolated from mouse and rat brain and sequences of UCP4 cDNAs were cloned. The deduced amino acid sequences of mouse, rat, and human UCP 4 sequences were compared. The amino acid sequence of mouse UCP4 shares 89 and $94 \%$ identity with human and rat UCP4, respectively (Fig. 1A). Rat UCP4 exhibits only $44 \%$ homology with rat UCP5/BMCP1, another UCP found mainly in the brain (Mao et al., 1999) and about 30\% identity is shown with UCP1. The amino acid sequence of mouse UCP4 includes three consecutive similar sequences of about 100 amino acids, six transmembrane domains, three putative mitochondrial energy transfer protein motifs located within hydrophilic regions (red) between the transmembrane domains and a putative purine nucleotide binding site (Fig. 1A, red box; Mao et al., 1999). Molecular modeling analysis of the 3D structure of the UCP4 protein (Fig. 1B) indicates a conformation with six transmembrane $\alpha$-helices, based on homology modeling of the X-ray crystallographic structure of the bovine mitochondrialADP/ATP carrier, a well-characterized mitochondrial anion carrier protein which shares $30 \%$ homology with UCP4.

\section{UCP4 is Expressed Predominantly in Neurons Throughout the Rodent Brain}

RT-PCR analysis of RNA samples from several different tissues and brain regions demonstrate that UCP 4 mRNA was present in all brain regions examined (cerebral cortex, hippocampus, striatum, and cerebellum), but was undetectable in heart, skeletal muscle, and liver (Fig. 2A). UCP4 mRNA was present at high levels in neuronenriched cultures of hippocampal (Fig. 2B) and cortical (data not shown) cells, at moderate levels in a transformed oligodendrocyte cell line (OLN93) and at low levels in astrocyte-enriched cortical cultures (Fig. 2B). Immunoblot analysis showed that UCP4 protein is present throughout the brain and appear to vary somewhat among brain regions (Fig. 2C).

In situ hybridization with ${ }^{35}$ S-labeled riboprobes was employed to establish the regional and cellular 

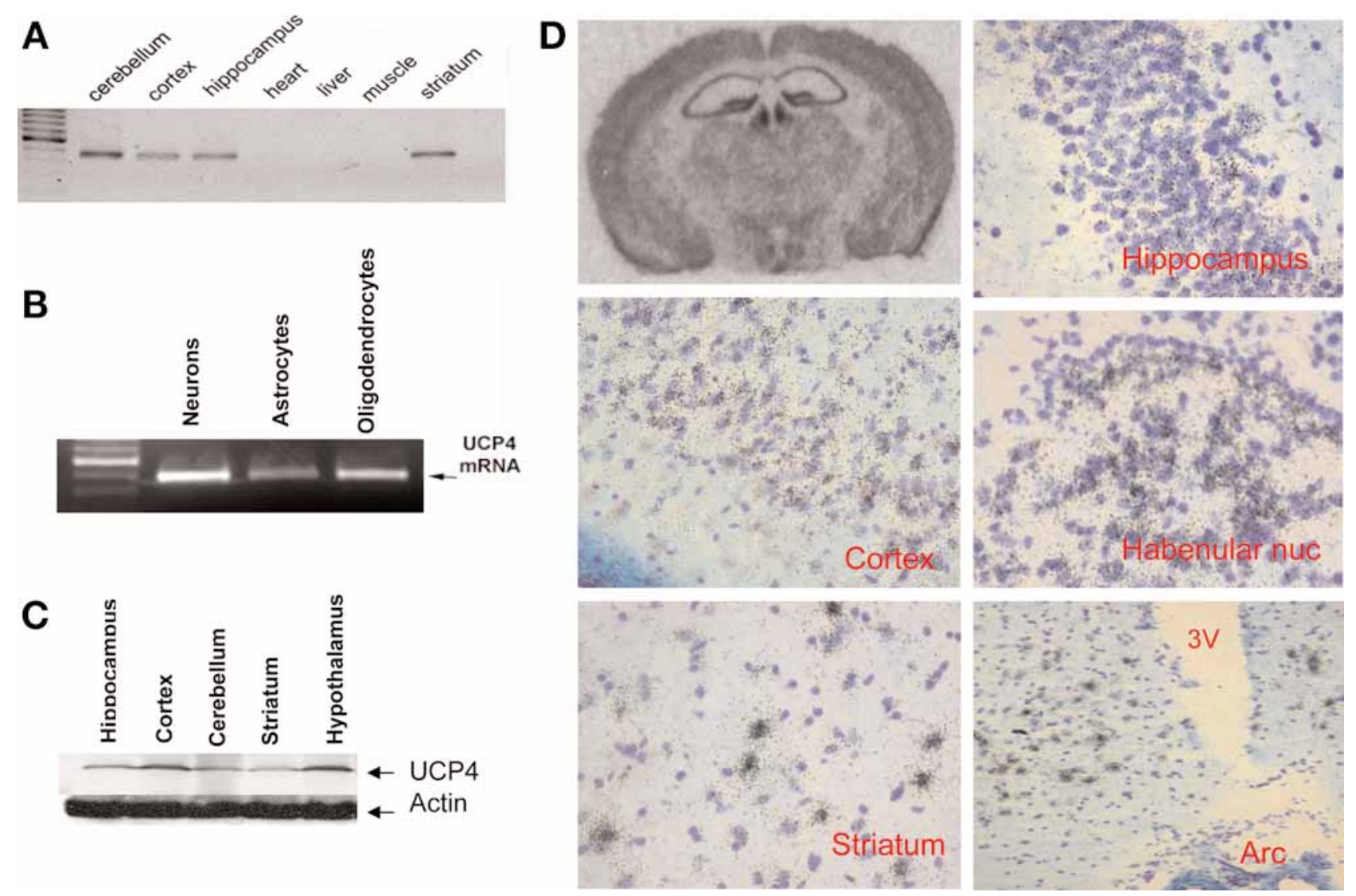

Fig. 2. Regional and cellular distribution of UCP4 in rodent brain. (A) RT-PCR analysis showing that UCP4 mRNA is present in multiple regions of rat brain, but is not detectable in heart, liver, or skeletal muscle. (B) Levels of UCP4 mRNA are higher in cultured rat hippocampal neurons as compared with cultured astrocytes and an oligodendrocyte cell line. (C) Immunoblot showing relative levels of UCP4 protein in the indicated brain regions of a mouse. (D) The upper left panel shows an autoradiograph of in situ hybridization with ${ }^{35}$ S-labeled riboprobes showing the distribution of UCP4 mRNA in a coronal section of mouse brain. The other five panels are micrographs of emulsion preparations showing the cellular localization of UCP4 mRNA in striatum, hippocampus (CA3 region), cortex, habenular nucleus, and arcuate nucleus.

distribution of UCP4 mRNA in the adult rodent brain. Autoradiographs revealed high levels of UCP4 mRNA in hippocampal pyramidal neurons and dentate granule cells, in the habenular nucleus, in the paratenial nucleus of the thalamus, and in the arcuate nucleus of thehypothalamus(Fig.2D; Table1). Moderatelevels of UCP4 mRNA were present in cells of the cerebral cortex, septal region, basal ganglia, and cerebellum (Table 1). Emulsion autoradiographs showed subpopulations of neurons in the striatum, and habenular and arcuate nuclei that expressed very high levels of UCP4 mRNA(Fig. 2D). Specific signal was also present in association with pyramidal neurons and dentate granule neurons in the hippocampus, and with scattered cells throughout the hypothalamus.

\section{hUCP4 Expression Alters $\mathrm{O}_{2}$ Consumption Rates and Reduces $\Delta \psi_{m}$ ROS Production, and $\mathrm{Ca}^{2+}$ Accumulation}

In order to elucidate the functions of UCP4 in neurons, the authors generated lines of PC12 neuronal cells that stably overexpress human UCP4 cells. Clones were selected that contained hUCP4 protein at moderately high amounts, as determined by RTPCRanalysis of mRNAlevels and immunoblot analysis of hUCP4 protein levels (Fig. 3A,B). Immunoblot analyses of whole cell lysates and isolated mitochondrial fractions demonstrated that hUCP4 protein was present in the mitochondrial fraction of cells transfected with the UCP4 plasmid, but was absent 
Table 1

Regional Expression of UCP4 mRNA in the Rat Brain

\begin{tabular}{|c|c|}
\hline Brain region & UCP4 mRNA level \\
\hline \multicolumn{2}{|l|}{ Cerebral cortex } \\
\hline Cingulate gyrus & ++ \\
\hline Frontal cortex & ++ \\
\hline Parietal cortex & ++ \\
\hline Pyriform cortex & +++ \\
\hline \multicolumn{2}{|l|}{ Hippocampus } \\
\hline CA1 & +++ \\
\hline CA3 & +++ \\
\hline Dentate gyrus & ++++ \\
\hline Habenular nucleus & ++++ \\
\hline \multicolumn{2}{|l|}{ Basal ganglia } \\
\hline Subthalamic nucleus & +++ \\
\hline Striatum & ++ \\
\hline Substantia nigra & +++ \\
\hline \multicolumn{2}{|l|}{ Septal region } \\
\hline Triangular septal nucleus & +++ \\
\hline \multicolumn{2}{|l|}{ Thalamus } \\
\hline Paratenial nucleus & ++++ \\
\hline Anterodorsal nucleus & +++ \\
\hline Paraventricular nucleus & ++++ \\
\hline \multicolumn{2}{|l|}{ Hypothalamus } \\
\hline Paraventricular nucleus & +++ \\
\hline Suprachiasmatic nucleus & ++ \\
\hline Arcuate nucleus & ++++ \\
\hline Dorsomedial nucleus & +++ \\
\hline Ventromedial nucleus & +++ \\
\hline Anterior hypothalamic nucleus & ++ \\
\hline Lateral hypothalamic nucleus & ++ \\
\hline \multicolumn{2}{|l|}{ Cerebellum } \\
\hline Granule layer & +++ \\
\hline Purkinje layer & ++ \\
\hline Corpus callosum & ++ \\
\hline Amygdala & + \\
\hline
\end{tabular}

+, low; ++, moderate; +++, high; ++++, very high.

in VT cells. The subcellular location of hUCP4 in the transfected cells is consistent with that previously reported for cells transfected with Flag-hUCP4 which colocalized with cytochrome-c oxidase when expressed in MCF7 cells (Mao et al., 1999).

To evaluate the functional activity of UCP4, the rates of oxygen consumption at states 3 and 4 were measured in digitonin-permeabilized UCP4 and VT cells (Table 2). Digitonin permeabilizes the plasma membrane but does not have, at the concentration used here $(0.001 \%)$, any detectable effect on the integrity of mitochondrial membranes as determined in TMRE loaded cells (data not shown). The $\mathrm{O}_{2}$ consumption rates of UCP4 cells was significantly lower than VT cells in state $3(p<0.01)$ and higher in state 4 ( $p=0.03$; paired one-tail $t$-test). The RCR(state 3/state4) was significantly lower in UCP4 cells than in VT cells $(p<0.01)$. The respiration rate of UCP4 cells was also lower in the presence of NADH-linked substrates (glutamate/malate, $0.001 \%$ digitonin, data not shown) but showed higher sensitivity to GDP ( $2 \mathrm{mM}, p=0.005)$. Oligomycin (state 4) inhibited about $75 \%$ of $\mathrm{O}_{2}$ consumption in VT cells but only $63 \%$ in UCP4 cells $(p<0.05)$ whereas the portion of GDP-sensitive respiration was increased in UCP 4 cells (45\%) compared with that in VT cells (25\%) (Table 2). Thus, UCP4 expression results in a shift from oligomycin sensitive to GDP-sensitive $\mathrm{O}_{2}$ consumption. The lower oxygen-consumption rate of UCP4 cells at state 3 (closest to physiological conditions) indicates $F_{1} \mathrm{~F}_{0} \mathrm{ATP}$ synthase activity was lower in UCP4 cells and that UCP4 expression induces an adaptive shift of energy metabolism from mitochondrial oxidative phosphorylation. The GDPsensitive respiration of UCP4 and VT cells were not measured at state 4 because the respiration rates after exposure to oligomycin were too low. The higher GDP sensitivity of UCP4 cells argues against a possible nonspecific effect of UCP4 expression on mitochondrial respiration and $\Delta \psi_{\mathrm{m}}$ (Stuart et al., 2001).

The effect of UCP4 expression on $\Delta \psi_{\mathrm{m}}$ at state 4 was further examined with time-lapse confocal imaging on UCP4 and VT cells loaded with TMRE and treated with oligomycin in the presence of ADP and succinate as substrates (Fig. 4). The experiments were performed without digitonin (Fig. 4A) or with digitonin $(0.001 \%$; Fig. 4B,C), as well as with rotenone to block reverse electron flow (Fig. 4C). In response to oligomycin, hyperpolarization of $\Delta \psi_{\mathrm{m}}$ was observed in VT cells over a period of several minutes but less response was observed in UCP4 cells under all conditions (Fig. 4A-C). The transient decrease of $\Delta \psi_{\mathrm{m}}$ induced by succinate (Fig. $4 \mathrm{~B}$ ) is likely because of the enhanced respiration and mitochondrial reverse electron flow as it was attenuated in the presence of rotenone (Fig. 4C). Stimulation of respiration by succinate in cultured cells has been reported previously (Il'chenko et al., 2005). The UCP4 cells also exhibited a higher hyperpolarization of $\Delta \psi_{\mathrm{m}}$ in response to GDP (1 mM; Fig. 4D), consistent with our respiration data showing that UCP4 cells were more sensitive to GDP (Fig. 3E,F). 

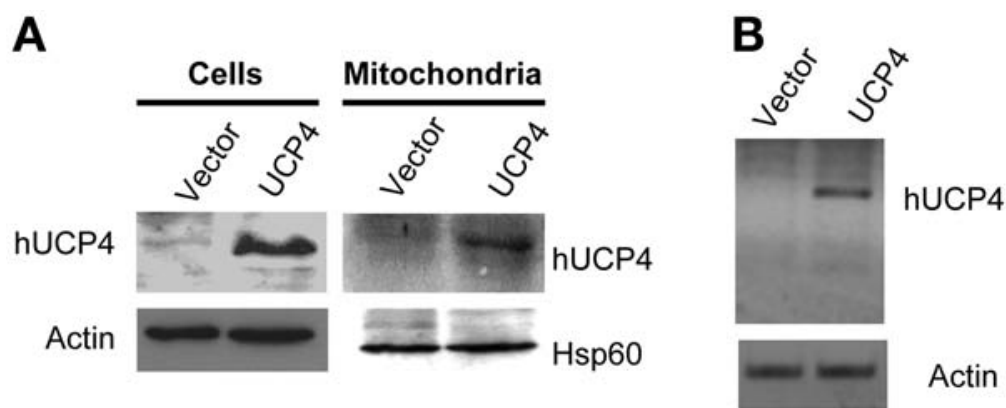

Fig. 3. Characterization of neural cells with elevated UCP4 levels. (A) Immunoblot showing UCP4 protein levels in whole cell lysates and isolated mitochondrial fraction of PC1 2 cell lines transfected with hUCP4 or empty vector. (B) RT-PCR analysis showing hUCP4 mRNA in PC12 cells transfected with UCP4 or empty vector.

Table 2

Effects of UCP4 Overexpression on Oxygen Consumption in PC12 Cells

\begin{tabular}{lccccc}
\hline & State 3 & State 4 & RCR (state 3/state 4) & $\begin{array}{c}\text { Oligomycin } \\
\text { inhibition (\%) }\end{array}$ & $\begin{array}{c}\text { GDP-sensitive } \\
\text { inhibition (\%) }\end{array}$ \\
\hline Vector & $58.4 \pm 6.1$ & $14.4 \pm 1.4$ & $3.72 \pm 0.57$ & $75.2 \pm 1.5$ & $25.6 \pm 15.1$ \\
hUCP4 & $53.6 \pm 5.3^{c}$ & $19.9 \pm 5.2^{d}$ & $2.75 \pm 0.38^{c}$ & $63.1 \pm 6.8^{e}$ & $45.7 \pm 10.9^{c}$ \\
\hline
\end{tabular}

Data were recorded in digitonin-permeabilized (0.001\%) UCP4 and vector-transfected cells and represented as ng atom $\mathrm{O} / \mathrm{min} / 1 \times 10^{7}$ cells. Values of state 3 and state 4 are the mean and SD $(n=8$ independent experiments). Respiration-control ratio (RCR) is the ratio of state $3 /$ state 4 respiration.

${ }^{a}$ Oligomycin sensitive inhibition of oxygen consumption (\%) was calculated based on measurements at state 3 and state 4 .

${ }^{b}$ GDP-sensitive inhibition (\%) was measured in HEPES-buffered saline with NADH-linked substrates (glutamate/malate) before and after the addition of GDP $(2 \mathrm{mM})$. Values are the mean \pm SD $(n=4$ independent experiments).

${ }^{c} p<0.05$

$d_{p}<0.01$ for significant differences between vector and hUCP4 cells based on paired two tail $t$-test.

${ }^{e} p<0.05$ based on paired one-tail $t$-test.

The authors further evaluated the impact of UCP4 on mitochondrial physiology by measuring $\Delta \psi_{\mathrm{m}}$ using the probe TMRE, levels of cellular ROS using the probes $\mathrm{CM}-\mathrm{H}_{2} \mathrm{DCFDA}$ (DCF) and DHR, and the intramitochondrial $\mathrm{Ca}^{2+}$ concentration using the probe Rhod-2. UCP4 cells exhibited a significantly lower level of TMRE fluorescence compared to VT cells as determined by confocal microscopy and flow cytometry (Fig. 5A,B). UCP4 cells exhibited significantly lower levels of DCF fluorescence (Fig. 5C) and dihydrorhodamine fluorescence (Fig. 5D) compared to VT cells, suggesting that UCP4 suppresses mitochondrial ROS production. Levels of Rhod-2 fluorescence were significantly lower in UCP4 cells compared to VT cells (Fig. 5E,F), suggesting that $\mathrm{UCP} 4$ reduces mitochondrial $\mathrm{Ca}^{2+}$ accumulation.

\section{UCP4 Induces a Shift in Energy Metabolism Characterized by Increased Glucose Uptake and Increased Glycolysis}

To determine the effects of UCP4 on cellular energy metabolism, the authors first measured ATP concentrations in lysates of VT and UCP4 cells. The ATP concentrations in VT and UCP cells were not significantly different under basal culture conditions (Fig. 6A). However, when the cells were exposed to FCCP, an uncoupler of mitochondrial oxidative 

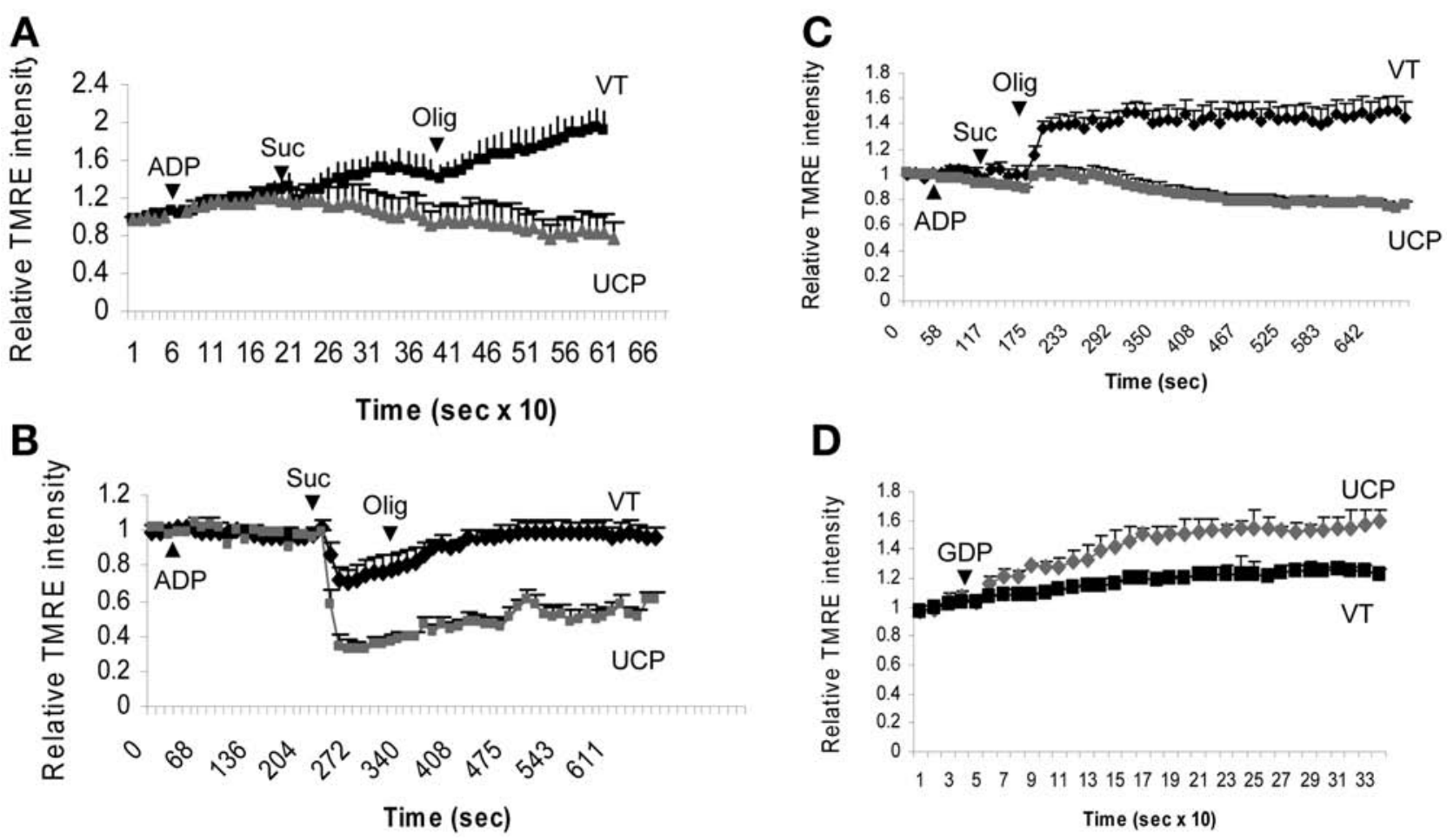

Fig. 4. The mitochondrial membrane potential $\left(\Delta \psi_{\mathrm{m}}\right)$ was monitored with time-lapse confocal imaging in UCP4 (gray) and vector-transfected (VT) control (black) cells loaded with TMRE (25 nM). (A-C) The $\Delta \psi_{\mathrm{m}}$ of UCP4 expressing cells was recorded when exposed to oligomycin $(2 \mu \mathrm{M}$, Olig) in buffer without digitonin (A) or with digitonin $(0.001 \%, B$ and $C)$; without rotenone $(A, B)$ or with rotenone $(2 \mu M, C)$. Exposure to oligomycin-induced hyperpolarization in VT cells but not UCP4 cells in all tested conditions in the presence of $0.3 \mathrm{mMADP}$ and $5 \mathrm{mM}$ succinate (Suc). Adding succinate induced a transient depolarization of $\Delta \psi_{\mathrm{m}}$ in the presence of digitonin (B), but this was attenuated in the presence of rotenone (C) The data represent measurements made in 80-90 cells from 11 separate experiments. (D) The $\Delta \psi_{\mathrm{m}}$ was monitored in UCP4 and VT cells before and during exposure to GDP $(1 \mathrm{mM})$ in buffer containing NADH linked substrates (glatamate/malate). The hUCP4 expressing cells showed a greater hyperpolarization response of $\Delta \psi_{\mathrm{m}}$ comparing to $\mathrm{VT}$ cells. The data represent measurements from 60 to 70 cells processed from seven separate experiments.

phosphorylation, ATP was significantly depleted from VT cells, but was maintained at a significantly higher level in UCP4 cells (Fig. 6A), suggesting that UCP4 causes a reduction in mitochondrial ATP production, which is compensated by an alternative pathway for ATP production. The latter findings further demonstrate that UCP4 activity makes neural cells less reliant on mitochondrial respiration for maintenance of energy levels.

The authors then performed a series of experiments to determine how neuronal energy metabolism is modulated by UCP4. Because glucose is the major substrate for ATP production, the authors evaluated glucose transport in control and UCP4expressing neural cells. The rate of ${ }^{3} \mathrm{H}$-glucose uptake was significantly greater in UCP4 cells compared to VT cells (Fig. 6B). Similarly, the uptake of the fluorescent glucose analog $2-(N-[7$ nitrobenz $]-$ 2-oxa-1-3-diazol-4-yl) amino 2- deoxyglucose (2-NBDG) was significantly greater in UCP4 cells compared with that of VT cells (Fig. 6C,D). Neurons can use lactate as an energy source, which might be particularly important for their function and survival under conditions of reduced oxygen availability or oxidative stress. Levels of lactate were more than twofold greater in UCP4 cells compared to VT cells (Fig. 6E). The decreased reliance of UCP4 cells on mitochondrial oxidative phosphorylation, and their increased uptake of glucose and lactate production suggested that UCP4 induces a shift to 

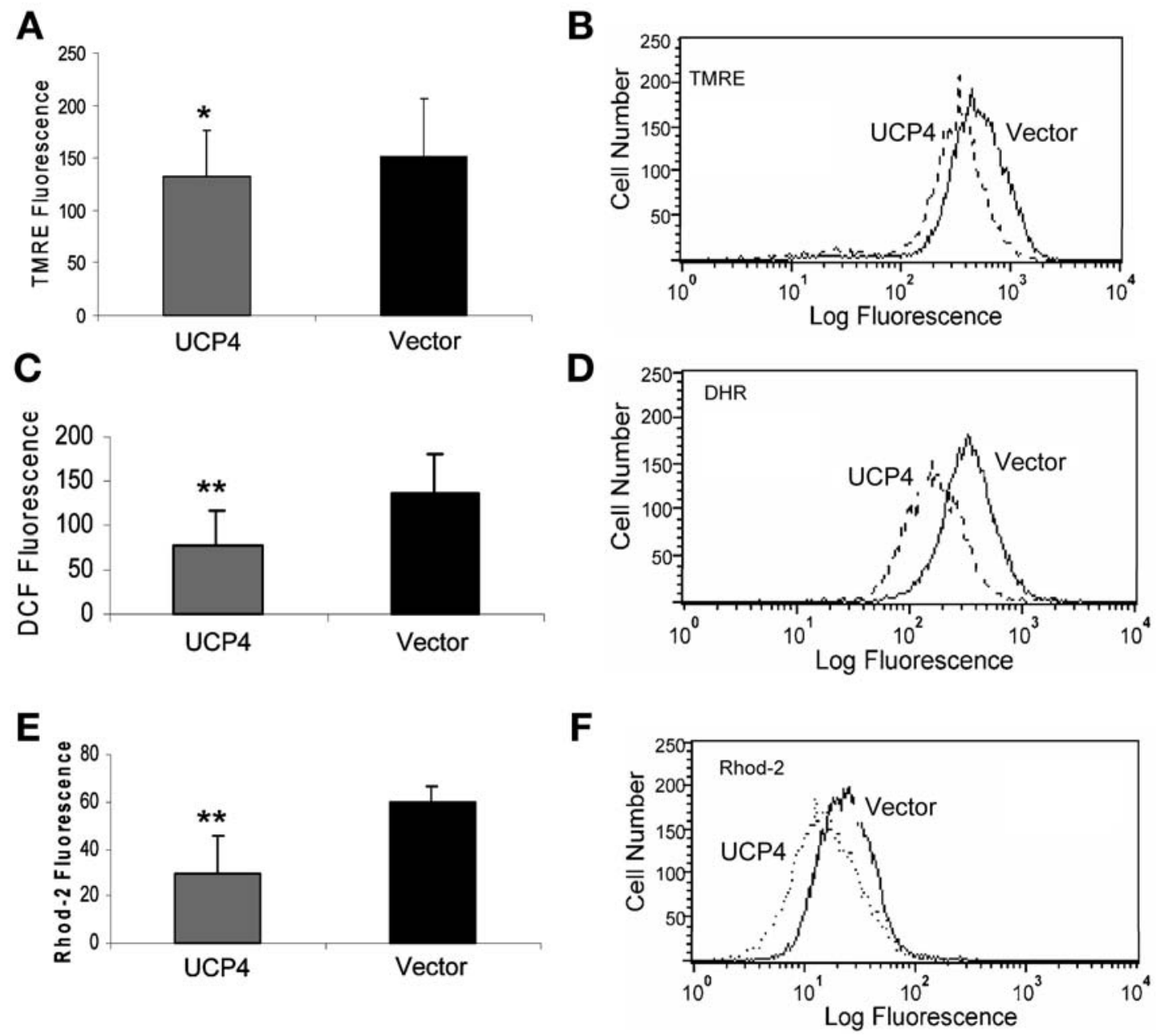

Fig. 5. Mitochondrial membrane potential (TMRE), ROS levels (DCF and DHR), and mitochondrial calcium concentration (Rhod2) were measured by confocal microscopy $(\mathbf{A}, \mathbf{C}, \mathbf{E})$ and flow cytometry $(\mathbf{B}, \mathbf{D}, \mathbf{F})$ in hUCP4 and vector-transfected cells. (A,B) Mitochondrial membrane potential (TMRE fluorescence). (C,D) Levels of mitochondrial reactive oxygen species (DHR fluorescence). (E,F) Mitochondrial calcium concentration (Rhod2 fluorescence). For bar graphs values are the mean and SD (average pixel intensity per cell of 10-20 cells per culture; $n=3$ cultures). ${ }^{*} p<0.05,{ }^{* *} p<0.01$. Flow cytometric analysis of TMRE, DHR and rhod-2 fluorescences revealed a shift of fluorescence intensity in UCP4 cells, indicating decreased $\Delta \psi_{m}$, ROS production and $\mathrm{Ca}^{2+}{ }_{\mathrm{m}}$ in UCP4 cells.

glycolytic energy metabolism. Consistent with the latter interpretation, we found that UCP4 cells exhibited increased sensitivity to inhibition of glycolysis. Thus, UCP4 cells were significantly more vulnerable to being killed by iodoacetate (an inhibitor of the glycolytic enzyme glyceraldehyde-3-phosphate dehydrogenase) compared to VT cells (Fig. 6F). Collectively, these results suggest that UCP4 reduces mitochondrial oxidative phosphorylation and ROS production, changes that are associated with enhanced glucose uptake and glycolysis.

\section{UCP4 Protects Neurons Against Mitochondrial Impairment and Oxidative Stress}

Mitochondrial stress plays a pivotal role in neuronal death in many physiological and pathological settings (Mattson and Kroemer, 2003). Because 

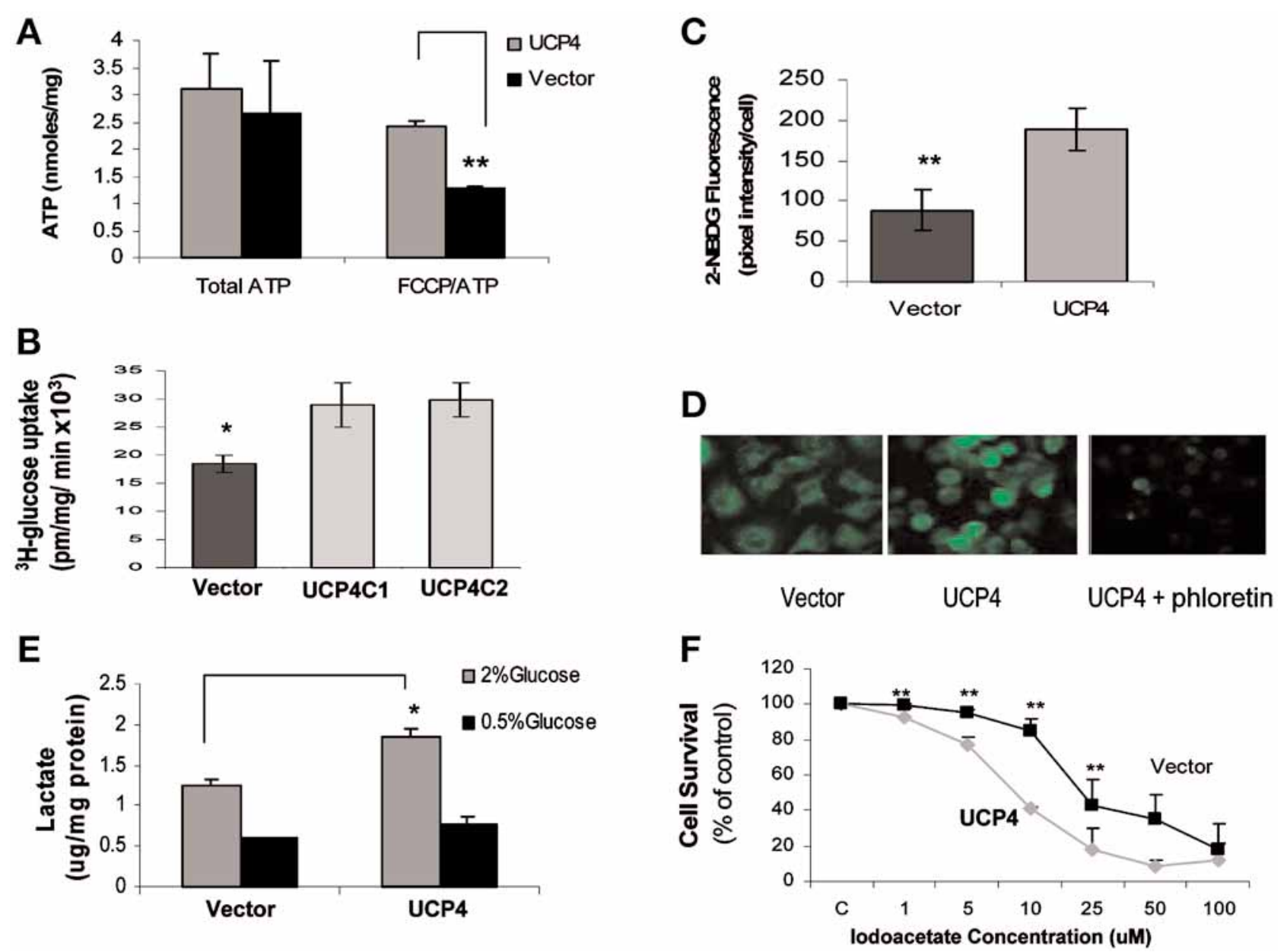

Fig. 6. UCP4 mediates a shift in energy metabolism characterized by increased glucose uptake and reliance on glycolysis. (A) ATP concentrations were measured in lysates of vector-transfected (VT) control and UCP4 PC12 cells under basal conditions and after $1 \mathrm{~h}$ of exposure to $2 \mu \mathrm{M}$ FCCP. Values are the mean and SD ( $n=10 \mathrm{cul}-$ tures) and ${ }^{* *} p<0.01$. (B) ${ }^{3} \mathrm{H}$-glucose uptake was measured in VT control and UCP4 cells. Values are the mean and SD ( $n=5$ cultures). ${ }^{*} p<0.05$. (C) Micrographs showing images of 2-NBDG (2-[N- $\{7$ nitrobenz $\}$-2-oxa-1-3diazol-4-yl] amino 2- deoxyglucose) fluorescence in untreated VT control cells and UCP4 cells, and in UCP4 cells that had been treated with phloretin (an inhibitor of glucose transport). (D) Values of 2-NBDG fluorescence in VT and UCP4 cells. Values are the mean and SD ( $n=8$ cultures) and $* * p<0.01)$. (E) Lactate production was measured in $\mathrm{VT}$ and $\mathrm{UCP} 4$ cells incubated in medium containing either $2 \%$ or $0.5 \%$ glucose. Values are the mean and SD ( $n=5-6$ cultures) and ${ }^{*} p<0.05$. (F) VT and UCP4 cells were exposed for $3 \mathrm{~h}$ to the indicated concentrations of iodoacetate and cell survival was quantified by trypan blue exclusion assay. Values are the mean and SD ( $n=4$ cultures) and ${ }^{* *} p<0.01$.

an increase in levels of UCP4 resulted in decreased $\Delta \psi_{\mathrm{m}}$, lower levels of ROS and reduced mitochondrial $\mathrm{Ca}^{2+}$ accumulation and decreased the reliance of neural cells on oxidative phosphorylation, we determined whether UCP4 can protect neurons against mitochondria-mediated cell death. VT and $\mathrm{UCP} 4$ cells were exposed to the mitochondrial toxin 3-nitropropionic acid (3NP), an inhibitor of succinate dehydrogenase (complex II) that impairs mitochondrial ATP production and induces oxidative stress and death of neurons (Brouillet et al., 1995). $3 \mathrm{NP}$ induced apoptosis of more than $10 \%$ of the VT cells within $12 \mathrm{~h}$ and more than $30 \%$ within $24 \mathrm{~h}$ (Fig. 7A). In contrast, UCP4 cells were significantly 

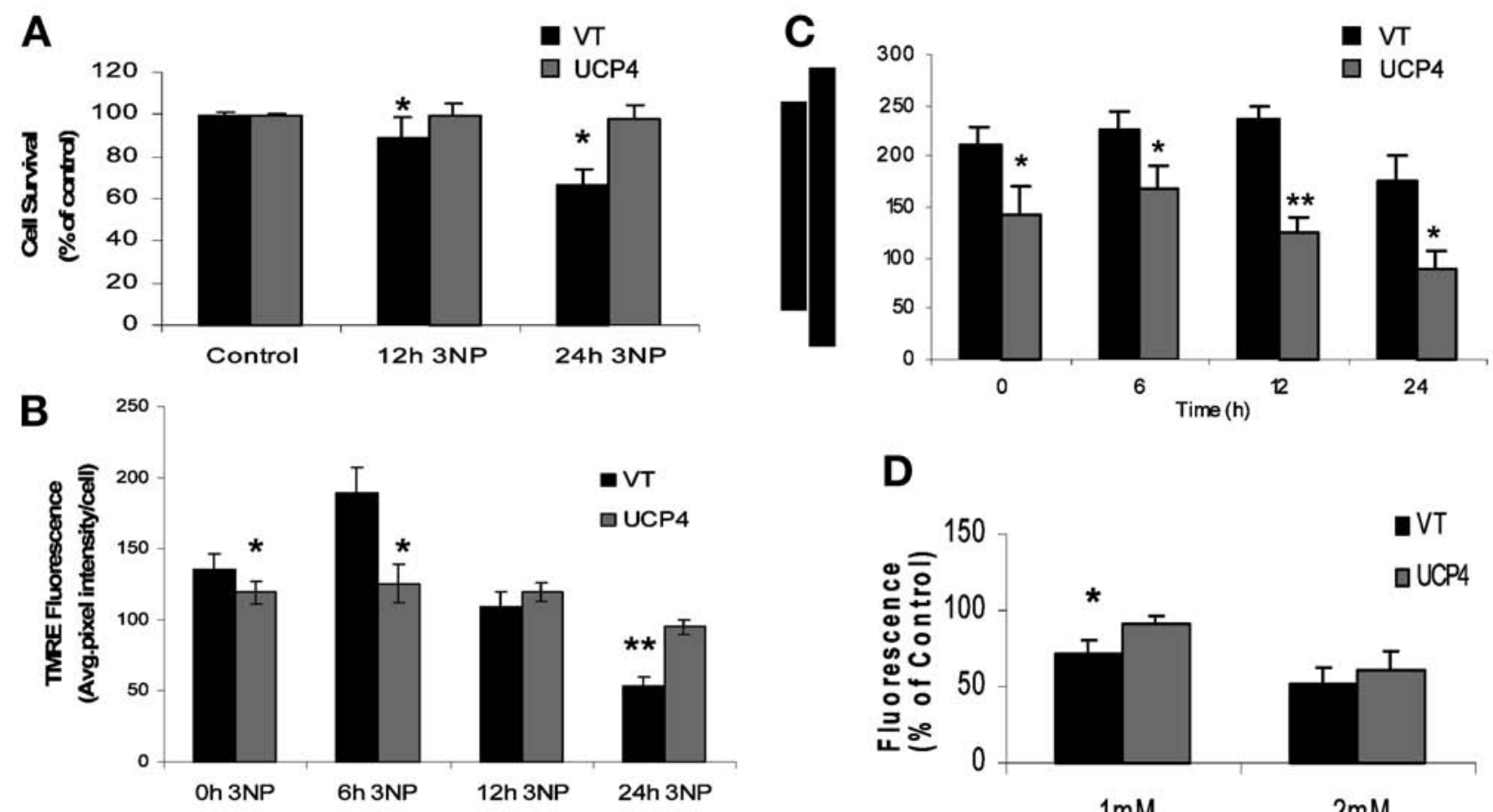

D

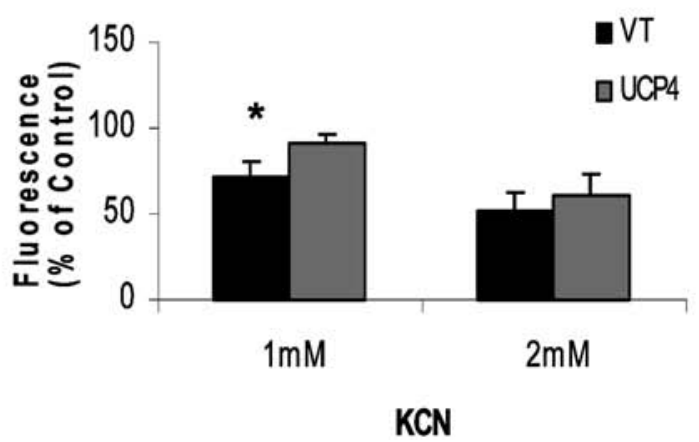

Fig. 7. Neural cells with increased UCP4 levels are less vulnerable to mitochondrial toxins and oxidative stress. (A) Cell survival was quantified in cultures exposed for 12 or $24 \mathrm{~h}$ to $20 \mathrm{mM} 3$-nitropropionic acid (3NP) or vehicle (control) by counting apoptotic nuclei. Values are the mean and SD ( $n=6$ cultures). ${ }^{*} p<0.05, * * p<0.01$. (B) Vector-transfected (VT) and UCP4 cells were exposed to $20 \mathrm{mM} 3 \mathrm{NP}$ for the indicated time periods and TMRE fluorescence (a measure of mitochondrial membrane potential) was quantified. Values are the mean and SD ( $n=5 \mathrm{cul}-$ tures). ${ }^{*} p<0.05,{ }^{* *} p<0.01$. (C) VT and UCP4 cells were exposed to $20 \mathrm{mM} 3 \mathrm{NP}$ for the indicated time-periods and dichlorofluorescein diacetate fluorescence (a measure of ROS) was quantified. Values are the mean and SD $(n=5$ cultures). ${ }^{*} p<0.05,{ }^{* *} p<0.01$.D. (D) UCP4 and VT cells were exposed to potassium cyanide (KCN, 1 or $\left.2 \mathrm{mM}\right)$ for $24 \mathrm{~h}$. Values are the mean and SD ( $n=4$ cultures) and expressed as percentage of changes of fluorescence intensity over control. ${ }^{*} p<0.05$.

more resistant to apoptosis induced by 3NP. Measurements of $\Delta \psi_{\mathrm{m}}$ in VT cells at increasing timepoints after exposure of cells to $3 \mathrm{NP}$ revealed a significant increase of $\Delta \psi_{\mathrm{m}}$ at $6 \mathrm{~h}$ followed by a progressive decrease to very low levels by $24 \mathrm{~h}$ as cells died (Fig. 7B). A similar transient hyperpolarization of the mitochondrial membrane in response to mitochondrial toxins has been reported in previous studies (Poppe et al., 2001; Giovannini et al., 2002; Iijima et al., 2003). In contrast, there was no significant change of $\Delta \psi_{\mathrm{m}}$ in UCP4 cells during the 24-h period of exposure to 3NP. 3NP treatment resulted in an increase in ROS levels in both VT and UCP4 cells; however, the magnitude of the increase was significantly greater in VT compared to UCP4 cells (Fig. 7C). Cells overexpressing UCP4 were also more resistant to death induced by potassium cyanide (KCN), a mitochondrial complex IV inhibitor that induces chemical hypoxia and neuronal death (Dubinsky and Rothman, 1991) as measured by Alamar blue fluorescence assay (Fig. 7D). Overexpression of UCP4 did not affect the total mitochondrial volume significantly in PC12 cells because UCP4 and VT cells exhibited similar levels of labeling with MitoTracker Green, a fluorescent probe that accumulates in mitochondria independently of the $\Delta \psi_{\mathrm{m}}$ (data not shown). Overexpression of UCP4 had no affect on cell survival under 
basal culture conditions as determined by Alamar blue assay (Fig. 7D).

\section{UCP4 Deficiency Promotes Mitochondrial Calcium Overload and Cell Death in Hippocampal Neurons}

To establish the function of endogenous UCP4 in neurons we employed RNA interference technology to deplete UCP4 in cultured rat hippocampal neurons. Neurons were transfected with siRNA duplexes (21 nucleotides in length) directed against rat UCP4 mRNA (UCP4siRNA), or with control siRNA of the same nucleotide composition but a scrambled sequence (N-siRNA). As an additional control, we transfected the neurons with GAPDH siRNA. Because of the low transfection efficiency of primary neurons in culture $(<50 \%)$ we labeled UCP4 and GAPDH siRNAs with a green fluorescent tag to identify neurons that were successfully transfected (Fig. 8A). The effectiveness of UCP4 siRNA in depleting UCP4 mRNA was verified by quantitative RT-PCR analysis; UCP4-mRNA levels were unaffected in cells transfected with N-siRNA or an siRNA directed against the $3^{\prime}$ untranslated region of UCP4 mRNA (Fig. 8B,C). Neuronal survival in cultures transfected with UCP4 siRNA was decreased during a $72 \mathrm{~h}$ period compared to cells transfected with $N$-siRNA suggesting that endogenous UCP4 is required for the survival of hippocampal neurons in culture (Fig. 8D). The intramitochondrial $\mathrm{Ca}^{2+}$ concentration in neurons transfected with UCP4 siRNA was significantly increased compared to untransfected neurons in the same cultures after $24 \mathrm{~h} \mathrm{UCP} 4$ siRNA transfection (Fig. 8E,F). Collectively, these data suggest that UCP4 serves cell survival-promoting and $\mathrm{Ca}^{2+}$-regulating functions in primary hippocampal neurons.

\section{Caloric Restriction and Cold Temperature Induce Expression of UCP4 in Brain Cells}

Caloric restriction (CR) is a dietary manipulation that extends life span (Weindruch and Sohal, 1997) and can protect neurons against injury and improve functional outcome in animal models of stroke and neurodegenerative disorders (Bruce-Keller et al., 1999; Yu and Mattson, 1999; Maswood et al., 2004). The mechanisms by which CR prolongs life span and protects neurons against disease are not clear, but it is known that $\mathrm{CR}$ results in a decreased body temperature and increased insulin sensitivity and reduced mitochondrial oxidative stress (Roth, 2002; Mattson, 2003; Merry, 2004). To determine whether UCP4 plays a role in the responses of neurons to changing of temperature and energy availability, the authors measured levels of UCP4 mRNA in rat hippocampal cell exposed to cold and in the brains of Fischer 334 rats that had been maintained for 14 mo on either an ad libitum control diet or a CR $\operatorname{diet}(40 \%$ reduction in calories). Cold exposure significantly increased UCP4-mRNA levels in cultured hippocampal neurons (Fig. 9A,B). Levels of UCP4 mRNA were higher in the cerebral cortex of rats in the CR group compared to rats in the control group as assessed by in situ hybridization autoradiography (Fig. 9C,D). Immunoblot analysis showed that average levels of UCP4 protein were higher in the cerebral cortex and hippocampus of rats on the CR diet (four animals in each group) although this increase did not reach statistical significance (Fig. 9E,F). These findings suggest that UCP4 might mediate physiological responses of neurons to changes in dietary energy intake and temperature.

\section{Discussion}

The present findings establish UCP4 as a brainspecific mitochondrial protein that is highly enriched in neurons and is expressed at variable levels among populations of neurons throughout the brain. Our analyses of PC12 cells overexpressing UCP4 and of hippocampal neurons with levels of UCP4 reduced by RNA interference demonstrate important roles for UCP4 in promoting neuronal survival. Cells expressing UCP4 underwent a shift of energy metabolism to increase glucose uptake and glycolysis, thereby providing sufficient ATP to compensate for the reduced mitochondrial ATP production resulting from expression of UCP4 (Fig. 10). These adaptations result in decreased ROS production and preventing mitochondrial calcium overloading, which likely contribute to the increased resistance of neurons with high levels of UCP4 to mitochondrial stress. In vivo studies showed that the expression of UCP4 mRNA is increased in brain cells of rats subjected to CR, suggesting a role for UCP4 in adaptive responses of neurons to changes in energy intake.

The pattern of expression of UCP4 mRNA in the brain was similar in rats and mice, with high levels of expression in hippocampal pyramidal and dentate 

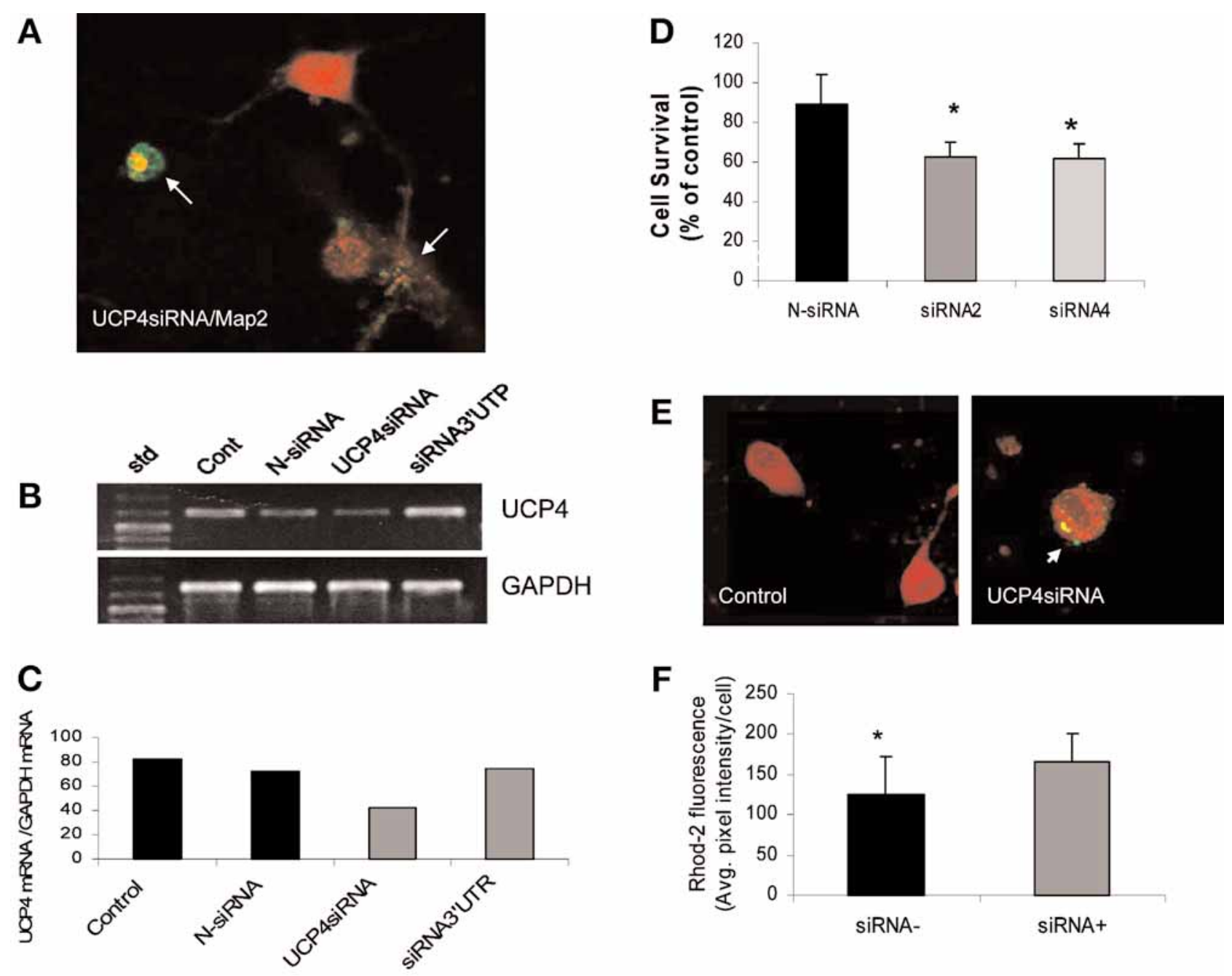

Fig. 8. Depletion of UCP4 renders hippocampal neurons vulnerable to cell death. (A) Confocal image of hippocampal neurons transfected with a UCP4 siRNA labeled with a green fluorescent tag and then immunostained with an antibody against the neuron-specific protein MAP2 (red). Arrows point to UCP4 siRNA transfected cells. (B and C) The effectiveness of UCP4 siRNA in depleting UCP4 mRNA was verified by quantitative RT-PCR analysis. Cultures were transfected with the indicated double-stranded RNAs or no RNA (Control) and $24 \mathrm{~h}$ later cells were lysed and RNA prepared for analysis. The level of UCP4 mRNA was normalized to the level of GAPDH mRNA in the same sample (C). (D) Hippocampal neurons were transfected with two different UCP4 siRNAs or scrambled RNA (N-siRNA). Neuronal survival was quantified $72 \mathrm{~h}$ after transfection. Values are the mean and SD of measurements in four to five cultures; ${ }^{*} p<0.05$ compared to the N-siRNA value. (E) Confocal images of Rhod-2 fluorescence in hippocampal neurons $24 \mathrm{~h}$ after transfection with scrambled control siRNA or UCP4 siRNA. (F) Quantification of Rhod-2 fluorescence intensity in hippocampal neurons $24 \mathrm{~h}$ after transfection with control or UCP4 siRNAs. Values are the mean and SD of measurements made in three to five cultures (10-20 neurons measured in each culture), ${ }^{*} p<0.05$. (See online version for color images.)

granule neurons, habenula, several hypothalamic nuclei (ventromedial, arcuate, paraventricular), the paratenial thalamic nucleus, and a subpopulation of striatal cells. There are similarities in the expression pattern of UCP4 documented in the present study and that previously reported for UCP5 (Sanchis et al., 1998), with both being expressed at high levels in similar populations of neurons in the hippocampus and 


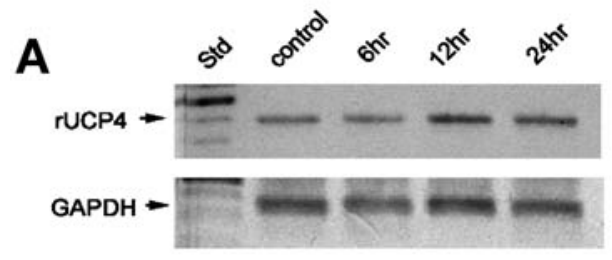

C

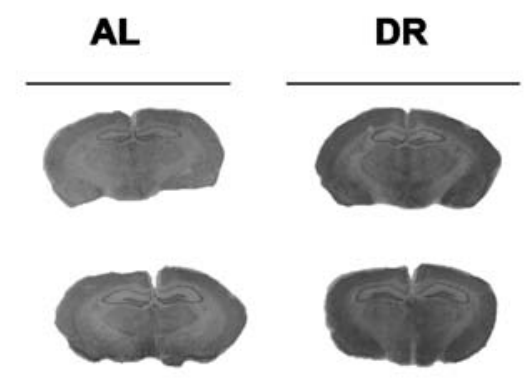

$\mathbf{E}$
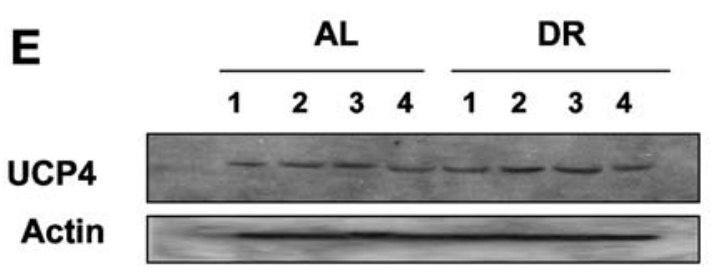
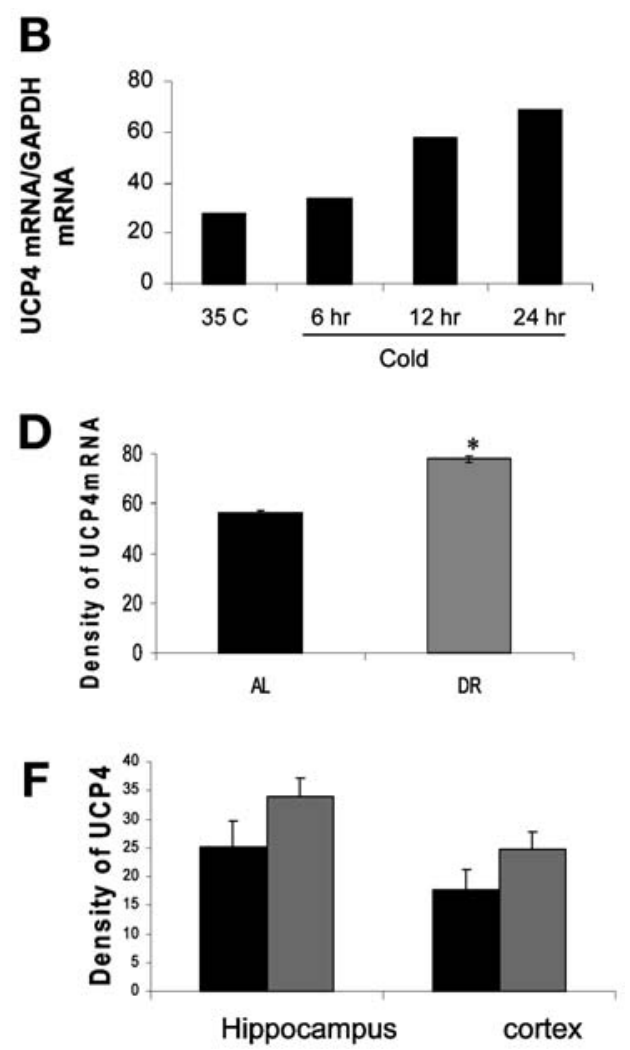

Fig. 9. Cold increases UCP4 expression in neuronal culture and caloric restriction induces the expression of UCP4 in the rat brain. (A) Cold exposure increases the UCP4 mRNA level in hippocampal cultures as detected by quantitative RT-PCR. (B) Quantification of ratio of UCP4 mRNA expression over GAPDH mRNA in the same sample. There was a 2.5 -fold increase of UCP4 mRNA expression following $24 \mathrm{~h}$ exposure to cold. (C) Representative in situ hybridization autoradiograms showing relative levels of UCP4 mRNA in brain sections from rats that had been maintained for 14 mo on either an ad libitum diet (AL) or a $40 \%$ caloric restriction diet (CR). (D) Optical density of UCP4 mRNA expression levels in the cerebral cortex of rats on AL and CR diets. Values are the mean and SD $\left(n=4\right.$ rats; $\left.{ }^{*} p<0.05\right)$. (E) Representative immunoblots showing relative levels of UCP4 protein in cerebral cortex tissue samples from four rats on the AL diet and four rats on the CR diet. (F) Results of densitometric analysis of immunoblots showing levels of UCP4 protein in hippocampal and cortical tissues from rats that had been maintained on either $\mathrm{AL}$ or CR diets. Values are the mean and $\mathrm{SD}(n=4$ rats).

hypothalamus. The expression of UCP2 is much more restricted, being present at high levels in some hypothalamic nuclei (paraventricular, arcuate, ventromedial, and suprachiasmatic nuclei), but with very low levels of expression in hippocampal and cortical cells (Richard et al., 1998).

Neurons in the ventromedial hypothalamic, habenular and arcuate nuclei, and the hippocampus play important roles in the regulation of energy metabolism and body weight as indicated by the upregulation of the leptin receptor in the latter brain regions in response to fasting in mice (Lin and Huang, 1997). There is also considerable overlap in the regional expression of UCP4 and glucokinase, the rate-limiting enzyme in glycolysis, which is thought to play a role in neuronal glucose sensing (Lynch et al., 2000). The latter study showed that glucokinase is highly expressed in neurons in the arcuate, ventromedial, paraventricular, and lateral nuclei of the hypothalamus, as well as in the habenular nucleus. By virtue of its connections with the central gray and raphe nucleus, and the substantia 


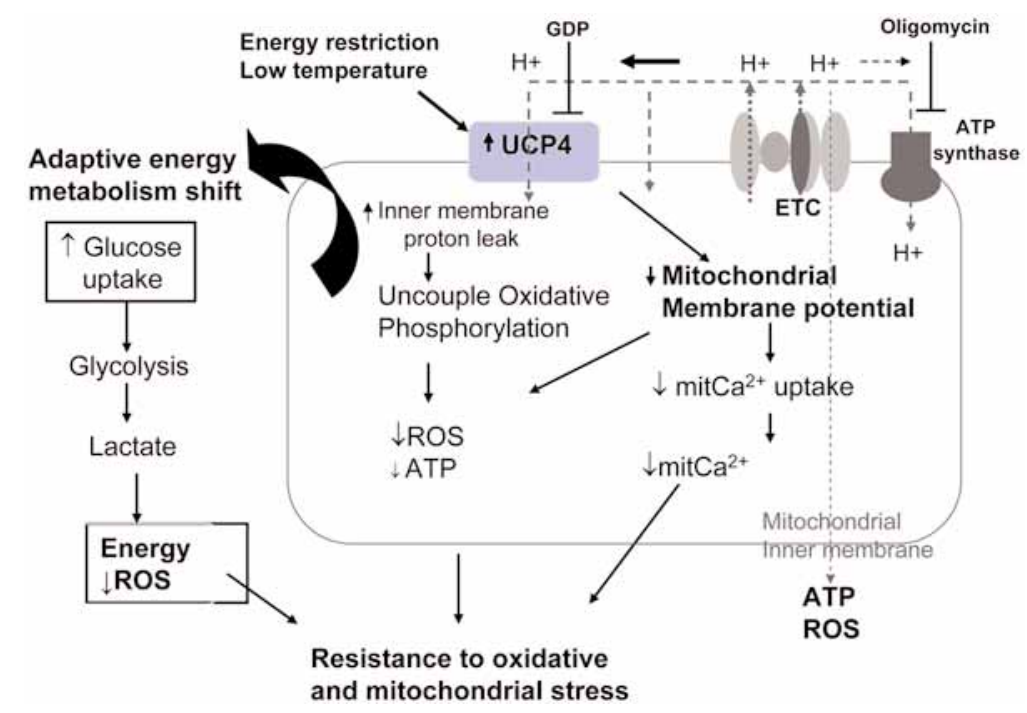

Fig. 10. Model of adaptive metabolism shifting and neuroprotective mechanism of UCP4. Increased UCP4 expression in neuron reduces $\Delta \psi_{\mathrm{m}}$ by increasing proton leak in the inner mitochondrial membrane, which reduces ROS produced in mitochondria and prevents mitochondrial calcium overload. UCP4 expression mediates an adaptive shift of energy metabolism by increasing glucose uptake and glycolysis to compensate for reduced mitochondrial ATP production from oxidative phosphorylation. ETC, electron transport chain.

nigra and ventral tegmental area, the habenular nucleus is believed to play important roles in modulating food intake and mood (Ellison, 1994). The distribution of UCP4 expression among brain structures also overlaps considerably with the expression of the receptor for glucagon-like peptide-1 (Merchenthaler et al., 1999), further suggesting a role for UCP4 in neuronal circuits that regulate energy balance. UCP4 levels were very high in a subpopulation of striatal neurons. Earlier studies have shown that, although medium spiny neurons in the striatum are vulnerable to metabolic compromise (Pisani et al., 2002), there are other types of striatal neurons that are resistant to being killed by metabolic insults, including exposure to 3NP (Brouillet et al., 1999) and focal cerebral ischemia (Kokaia et al., 1998). Some of the resistant neurons express NADPH diaphorase (nitric oxide-producing neurons) and some are cholinergic (Behrens et al., 1996; Kokaia et al., 1998). Because we found that UCP4 can protect neurons against metabolic and oxidative insults, it might be the case that the high levels of UCP4 serve a neuroprotective function in striatal neurons that might be subjected to high levels of oxidative stress, such as those that produce nitric oxide.
Energy intake and expenditure are tightly regulated processes. We found that cellular ATP levels were maintained in UCP4 cells compared to control cells even though the $\mathrm{O}_{2}$ consumption rate of UCP4 cells at state 3 respirations was significantly lower than VT cells. Apparently as an adaptive response cells with high UCP4 levels also had increased rates of glucose uptake. ATP levels were maintained at a relatively high level in UCP4 expressing cells but not in control cells following exposure to FCCP, an uncoupler that abolishes ATP production in mitochondria. The results indicate that a portion of ATP in UCP4 cells does not come from mitochondria and UCP4 might mediate an adaptive shift of ATP production from mitochondrial respiration to glycolysis (Fig. 6). In addition, a glycolytic shift in response to UCP4 expression is supported by the increased cellular lactate levels in cells with high-UCP4 levels and the increased vulnerability of UCP4 cells to iodoacetate, an inhibitor of glycolysis. Although glycolysis is more prominent in astrocytes, it also occurs in neurons and PC12 cells (Pereira et al., 1999; Gjedde and Marrett, 2001). Cells with a high glycolytic capability exhibit increased resistance to oxidative stress (Almeida et al., 2001; Brown and Bonitaite, 2001), consistent with a role for the glycolytic shift induced 
by UCP4 in protecting neurons against oxidative stress. It has been reported that levels of ATP are increased in brain cells of UCP2 transgenic mice which could be related to increased mitochondrial number as a result of mitochondrial proliferation (Diano et al., 2003). Our results showed that the total mitochondrial volume is not significantly different between UCP4 and VT cells as detected by labeling mitochondria with MitoTracker Green, a fluorescent probe that accumulates in mitochondria independently of the $\Delta \psi_{\mathrm{m}}$. Also the Alamar blue assay, which is based on the activity of mitochondrial enzymes, did not reveal a significant difference between UCP4 and VT cells under basal culture conditions (Fig. 6D).

The $\Delta \psi_{\mathrm{m}}$ of UCP4 cells was lower than that of control cells, consistent with previous studies of other UCPs (Mao et al., 1999; Yu et al., 2000). The reduction in $\Delta \psi_{\mathrm{m}}$ in PC12 cells overexpressing UCP4 is unlikely to be a nonspecific effect, because overexpression of other mitochondrial proteins resulted in divergent effects on $\Delta \psi_{\mathrm{m}}$ and ROS production. For example, overexpression of manganese superoxide dismutase did not affect $\Delta \psi_{\mathrm{m}}$, but was very effective in reducing ROS levels in neural cells exposed to different oxidative stressors (Keller et al., 1998). On the other hand, overexpression of $\mathrm{Bcl}-2$ resulted in increased mitochondrial membrane potential and reduced ROS levels in PC12 cells (Kowaltowski et al., 2000). Although the reduction of $\Delta \psi_{\mathrm{m}}$ in cells overexpressing UCP4 was modest (about 15\%), others have found that a 10\% decrease of $\Delta \psi_{\mathrm{m}}$ can result in a $50 \%$ reduction in ROS production (Korshunov et al., 1997).

The oxygen-consumption rate of UCP4 cells was lower than that of control cells at state 3 (which is close to physiological conditions) but not at state 4 (slightly higher) when cells were exposed to oligomycin, an inhibitor of $F_{0} \mathrm{~F}_{1}$ ATP synthase (Table 2) which indicates that the activity of $F_{0} \mathrm{~F}_{1}$ ATPase is lower in UCP4 cells at state 3 . The oxygenconsumption rate of UCP4 was also lower in buffer with NADH-linked substrates (glutamate/malate) which further supports the hypothesis that the ATP production might shift from mitochondrial oxidative phosphorylation to glycolysis. It was unlikely that the lower respiration rate at state 3 was because of a mechanism other than UCP4-mediated uncoupling because the lower $\Delta \psi_{\mathrm{m}}$ was observed in UCP4 cells under physiological culture conditions in which endogenous activators such as fatty acids and inhibitors such as nucleotides are always present. UCPs might not transport protons themselves. The uncoupling activity of UCPs requires transport of the anionic fatty acid head group across the bilayer and the proton transport might be mediated by the fatty acid and not by the UCP itself (Garlid et al., 2001). It has been shown that the rate of state 3 respiration is marginally lower in mitochondria isolated from yeast strains expressing UCP1-3, whereas state 4 respiration rate is increased in UCP1 and UCP2 but not UCP3 expressing strains (Rial et al., 1999). Our studies also showed that exposure to oligomycin induced a significant hyperpolarization of $\Delta \psi_{\mathrm{m}}$ in VT cells but not UCP4 cells, suggesting the presence of a higher proton conductance as a result of UCP4-mediated protonophoric function when the $F_{0} \mathrm{~F}_{1}$ ATPase was inhibited. Although it is not known if the oxygen-consumption rate of mitochondria in intact cells is different from that of isolated mitochondria, whole-cell respiration rates are a combination of mitochondrial and nonmitochondrial energy metabolism. Our findings suggest that UCP4 activity decreases $\Delta \psi_{\mathrm{m}}$ resulting in reduced mitochondrial ATP and ROS production and a shift to glycolysis that allows maintenance of ATP production. The latter interpretation is consistent with data showing that mitochondria-deficient cells are viable and depend on glycolysis for their energy requirements (Herst et al., 2004).

Studies of muscle, liver, and fat cells have demonstrated the responsiveness of UCP genes to several different stimuli including cold and heat exposure, feeding and fasting, free-fatty acids, and inflammatory cytokines (Boss et al., 1997; Busquets et al., 1998; Weigle et al., 1998; Yu et al., 2000; Argyropoulos and Harper, 2002). The factors that affect UCP expression in neurons are unknown. It was reported that cold exposure does not affect UCP2 and UCP5 mRNA levels in the brain, but that levels of UCP5 mRNA decrease and UCP2 mRNA levels increase during ageing in rats (Mizuno et al., 2000). UCP2 expression was induced by entorhinal cortex lesion, and UCP2 might increase the resistance of entorhinal neurons to apoptosis (Bechmann etal., 2002). Our results show that the UCP4-mRNA expression levels were higher in brain cells of energy-restricted rats. This increase in UCP4-mRNA expression may be the result of the decreased body temperature and/or reduced energy utilization during CR (Roth et al., 2002). In this regard, 
we have found that UCP4 levels are increased in cultured hippocampal neurons exposed to cold temperatures. Dietary restriction can protect neurons against oxidative and metabolic stress (Bruce-Keller etal., 1999; Maswood et al., 2004), suggesting a potential role of UCP4 in the neuroprotective effects of CR. Mutation in genes that encode mitochondrial proteins involved in oxidative phosphorylation can reduce oxidative stress and increase life span in $C$. elegans (Rea and Johnson, 2003). These mutants exhibit increased use of lactate or alcohol-producing fermentative pathways for energy production and reduced ROS production.

Neural cells with high UCP4 levels maintained an intramitochondrial $\mathrm{Ca}^{2+}$ concentration that was lower than that of control cells, whereas hippocampal neurons in which UCP4 levels were decreased using siRNAs exhibited an elevated intramitochondrial $\mathrm{Ca}^{2+}$ concentration. These findings suggest a role for $\mathrm{UCP} 4$ in the regulation of mitochondrial $\mathrm{Ca}^{2+}$ homeostasis in neurons. High concentrations of $\mathrm{Ca}^{2+}$ in mitochondria occur before cell death in many different pathological conditions including hypoxia (Fransteva et al., 2001) and excitotoxicity (Peng et al, 1998; Alano et al., 2002). Mitochondrial $\mathrm{Ca}^{2+}$ overload can impair oxidative phosphorylation and ATP synthesis, increase ROS production, and induce mitochondrial membrane permeability transition pore formation and apoptosis (Murphy and Fiskum, 1999; Gibson, 2002; Mattson and Kroemer, 2003). Stabilization of mitochondrial $\mathrm{Ca}^{2+}$ homeostasis by UCP4 might therefore contribute to its neuroprotective actions.

Recent findings suggest that UCP 2 and UCP 3 can protect neurons against ischemic injury (Mattiasson et al., 2003) and that increased levels of UCP2 are associated with increased resistance of neurons to excitotoxicity (Sullivan et al., 2003). In addition, dopaminergic neurons in UCP2-deficient mice exhibit increased vulnerability to the Parkinsonian toxin MPTP (Andrews et al., 2005). The authors found that neural cells with high-UCP4 levels were relatively resistant to being killed by $3 \mathrm{NP}$ and cyanide, mitochondrial toxins that kill neurons by a mechanism involving increased ROS generation and metabolic stress (Kim and Chan, 2001; Li et al., 2002). UCP4 expression attenuated the increase in ROS levels resulting from exposure of the cells to 3NP. It is therefore likely that the ability of UCP4 to suppress mitochondrial ROS production contributes to its neuroprotective actions. The shift in energy metabolism resulting from UCP4 expression also likely contributes to neuroprotection because of a decreased reliance of the cells on mitochondrial respiration. Hippocampal neurons in which UCP4levels were decreased by transfection of the cells with siRNAs directed against UCP4 mRNA were more vulnerable to death, demonstrating that endogenous UCP4 serves a cytoprotective function in neurons.

Our findings show that UCP4 is a neuronal mitochondrial protein that modulates energy metabolism pathway, ROS production, and $\mathrm{Ca}^{2+}$ homeostasis. Although the authors focused on the consequences of these activities of UCP4 for cell survival under conditions of metabolic and oxidative stress, the findings have implications for other aspects of neuronal function. For example, $\mathrm{Ca}^{2+}$, ROS, and energy metabolism play important roles in regulating synaptic transmission and plasticity (Chittajallu et al, 1998; Zorumski and Izumi, 1998; Knapp and Klann, 2002; Kann et al., 2003), and neurite outgrowth, and synaptogenesis (Haydon and Zoran, 1994; Mattson and Liu, 2002). It will therefore be of interest to determine the roles of UCP4 in such physiological processes.

\section{Acknowledgments}

This research was supported by the intramural research program of the National institute on Ageing of the NIH. The authors thank G. Pan and K. Gabrielson for providing UCP cDNAs, D. K. Ingram for providing brains from calorie restricted Fischer-344 rats, J. Stuart for help with the oxygen consumption assay, and E. Yavin and A. Cheng for providing oligodendrocyte and astrocyte cell cultures.

\section{References}

Alano C. C., Beutner G., Dirksen R. T., Gross R. A., and Sheu S. S. (2002) Mitochondrial permeability transition and calcium dynamics in striatal neurons upon intense NMDA receptor activation. J. Neurochem. 80, 531-538.

Almeida A., Almeida J., Bolanos J. P., and Moncada S. (2001) Different responses of astrocytes and neurons to nitric oxide: the role of glycolytically generated ATP in astrocyte protection. Proc. Natl. Acad. Sci. USA 98, 15,294-15,299. 
Andrews Z. B., Horvath B., Barnstable C. J., et al. (2005) Uncoupling protein-2 is critical for nigral dopamine cell survival in a mouse model of Parkinson's disease. J. Neurosci. 25, 184-191.

Andreyev A., Bondareva T., Dedukhova V. I., et al. (1989) The ATP / ADP-antiporter is involved in the uncoupling effect of fatty acids on mitochondria. Eur. J. Biochem. 182, 585-592.

Argiles J. M., Busquets S., and Lopez-Soriano F. J. (2002) The role of uncoupling proteins in pathophysiological states. Biochem. Biophys. Res. Commun. 293, $1145-1152$.

Argyropoulos G. and Harper M. E. (2002) Uncoupling proteins and thermoregulation. J. Appl. Physiol. 92, 2187-2198.

Arsenijevic D., Onuma H., Pecqueur C., et al. (2000) Disruption of the uncoupling protein-2 gene in mice reveals a role in immunity and reactive oxygen species production. Nat. Genet. 26, 435-439.

Beal M. F. (1998) Mitochondrial dysfunction in neurodegenerative diseases. Biochim. Biophys. Acta 1366, 211-223.

Bechmann I., Diano S., Warden C. H., Cartfai T., Nitsch R., and Horvath T. L. (2002) Brain mitochondrial uncoupling protein 2 (UCP2): a protective stress signal in neuronal injury. Biochem. Pharmacol. 64, 363-367.

Behrens M. I., Koh J. Y., Muller M. C., and Choi D. W. (1996) NADPH diaphorase-containing striatal or cortical neurons are resistant to apoptosis. Neurobiol. Dis. 3, 72-75.

Boss O., Samec S., Dulloo A., Seydoux J., Muzzin P., and Giacobino J. P. (1997) Tissue-dependent upregulation of rat uncoupling protein-2 expression in response to fasting or cold. FEBS Lett. 412, 111-114.

Brouillet E., Hantraye P., Ferrante R. J., et al. (1995) Chronic mitochondrial energy impairment produces selective striatal degeneration and abnormal choreiform movements in primates. Proc. Natl. Acad. Sci. USA 92, 7105-7109.

Brouillet E., Conde F., Beal M. F., and Hantraye P. (1999) Replicating Huntington's disease phenotype in experimental animals. Prog. Neurobiol. 59, 427-468.

Brown G. C. and Bonitaite V. (2001) Nitric oxide, mitochondria, and cell death. IUBMB Life 52, 189-195.

Bruce-Keller A. J., Umberger G., McFall R., and Mattson M. P. (1999) Food restriction reduces brain damage and improves behavioral outcome following excitotoxic and metabolic insults. Ann. Neurol. 45, 8-15.

Busquets S., Sanchis D., Alvarez B., Ricquier D., LopezSoriano F. J., and Argiles J. M. (1998) In the rat, tumor necrosis factor alpha administration results in an increase in both UCP2 and UCP3 mRNAs in skeletal muscle: a possible mechanism for cytokine-induced thermogenesis? FEBS Lett. 440, 348-350.

Cadenas S. and Brand M. D. (2000) Effects of magnesium and nucleotides on the proton conductance of rat skeletal-muscle mitochondria. Biochem. J. 348, 209-213.

Cabo R. D., Fürer-Gálban S., Anson R. M., Gilman C., Gorospe M., and Lane M. A. (2003) An in vitro model of caloric restriction. Exp. Gerontol. 38, 631-639.

Chan C. B., MacDonald P. E., Saleh M. C., John D. C., Marban E., and Wheeler M. B. (1999) Overexpression of uncoupling protein 2 inhibits glucosestimulated insulin secretion from rat islets. Diabetes 48, 1482-1486.

Chan S. L., Fu W., Zhang P., et al. (2004) Herp stabilizes neuronal $\mathrm{Ca}^{2+}$ homeostasis and mitochondrial function during endoplasmic reticulum stress. J. Biol. Chem. 279, 28,733-28,743.

Chittajallu R., Alford S., and Collingridge G. L. (1998) $\mathrm{Ca}^{2+}$ and synaptic plasticity. Cell Calcium 24, 377-385.

De Cabo R., Furer-Galban S., Anson R. M., Gilman C., Gorospe M., and Lane M. A. (2003) An in vitro model of caloric restriction. Exp. Gerontol. 38, 631-639.

Deshmukh M. and Johnson E. M. (1997) Programmed cell death in neurons: focus on the pathway of nerve growth factor deprivation-induced death of sympathetic neurons. Mol. Pharmacol. 51, 897-906.

Diano S., Matthews R. T., Patrylo P., et al. (2003) Uncoupling protein 2 prevents neuronal death including that occurring during seizures: a mechanism for preconditioning Endocrinology 144, 5014-5021.

Dubinsky J. M. and Rothman S. M. (1991) Intracellular calcium concentrations during "chemical hypoxia" and excitotoxic neuronal injury. J. Neurosci. 11, 2545-2551.

Duffy P. H., Feuers R., Nakamura K. D., Leakey J., and Hart R. W. (1990) Effect of chronic caloric restriction on the synchronization of various physiological measures in old female fischer 344 rats. Chronob. Int. 7, 113-124.

Dulloo A. G., Samec S., and Seydoux J. (2001) Uncoupling protein 3 and fatty acid metabolism. Biochem. Soc. Trans. 29, 785-791.

Echtay K. S., Roussel D., St-Pierre J., et al. (2002) Superoxide activates mitochondrial uncoupling proteins. Nature 415, 96-99. 
Echtay K. S., Esteves T., Pakay J. L., et al. (2003) A signaling role for 4-hydroxy-2-nonenal in regulation of mitochondrial uncoupling. EMBO J. 22, 4103-4110.

Ellison G. (1994) Stimulant-induced psychosis, the dopamine theory of schizophrenia, and the habenula. Brain Res. Rev. 19, 223-239.

Erlanson-Albertsson C. (2003) The role of uncoupling proteins in the regulation of metabolism. Acta Physiol. Scand. 178, 405-412.

Fransteva M. V., Carlen P. L., and Perez Velazquez J. L. (2001) Dynamics of intracellular calcium and free radical production during ischemia in pyramidal neurons. Free Radic. Biol. Med. 31, 1216-1227.

Garlid K. D., Jaburek M., and Jezek P. (2001) Mechanism of uncoupling protein action. Biochem. Soc. Trans. 29, 803-806.

Gibson G. E. (2002) Interactions of oxidative stress with cellular calcium dynamics and glucose metabolism in Alzheimer's disease. Free Radic. Biol. Med. 32, 1061-1070.

Giovannini C., Matarrese P., Scazzocchio B., Sanchez M., Masella R., and Malorni W. (2002) Mitochondria hyperpolarization is an early event in oxidized low-density lipoprotein-induced apoptosis in $\mathrm{CaCo}_{2}$ intestinal cells. FEBS Lett. 523, 200-206.

Gjedde A. and Marrett S. (2001) Glycolysis in neurons, not astrocytes, delays oxidative metabolism of human visual cortex during sustained checkerboard stimulation in vivo. J. Cereb. Blood Flow Metab. 21, 1384-1392.

Hagen T. and Lowell B. B. (2000) Chimeric proteins between UCP1 and UCP3: the middle third of $\mathrm{UCP} 1$ is necessary and sufficient for activation by fatty acids. Biochem. Biophys. Res. Commun. 276, 642-648.

Han D., Nolte L. A., Ju J., Coleman T., Holloszy J. O., and Semenkovich C. F. (2003) UCP-mediated energy depletion in skeletal muscle increases glucose transport despite lipid accumulation and mitochondrial dysfunction. Am. J. Physiol. Endocrinol. Metab. 286, E347-E353.

Hanak P. and Ježek P. (2001) Mitochondrial uncoupling proteins and phylogenesis-UCP4 as the ancestral uncoupling protein. FEBS Lett. 495, 137-141.

Haydon P. G. and Zoran M. J. (1994) Retrograde regulation of presynaptic development during synaptogenesis. J. Neurobiol. 25, 694-706.

Herst P. M., Tan A. S., Scarlett D. G., and Berridge M. V. (2004) cell surface oxygen consumption by mitochondrial gene knockout cells. Biochim. Biophys. Acta 1656, 70-87.
Hou S. T. and MacManus J. P. (2002) Molecular mechanisms of cerebral ischemia-induced neuronal death. Int. Rev. Cytol. 221, 93-148.

Huppertz C., Fischer B. M., Kim Y. B., et al. (2001) uncoupling protein 3 (UCP3) stimulates glucose uptake in muscle cells through a phosphoinositide3-kinase-dependent mechanism. J. Biol. Chem. 276, 12,520-12,529.

II-chenko A. P., Ogorelyshev D. I., Shishkanova N. V., Sokolov A. P., Finogenova T. V., and Kondrashova M. N. (2005) The effect of succinate on respiration, transamination, and pyruvate formation in cells of the yeast Dipodascus magnusii. Mikrobiologiia 74, 609-615.

IIjima T., Mishima T., Akagawa K., and Iwao Y. (2003) Mitochondrial hyperpolarization after transient oxygen-glucose deprivation and subsequent apoptosis in cultured rat hippocampal neurons. Brain Res. 993, 140-145.

Kann O., Schuchmann S., Bucheim K., and Heinemann U. (2003) Coupling of neuronal activity and mitochondrial metabolism as revealed by $\mathrm{NAD}(\mathrm{P}) \mathrm{H}$ fluorescence signals in organotypic hippocampal slice cultures of the rat. Neuroscience 119, 87-100.

Keller J. N., Kindy M. S., Holtsberg F. W., et al. (1998) Mitochondrial manganese superoxide dismutase prevents neural apoptosis and reduces ischemic brain injury: suppression of peroxynitrite production, lipid peroxidation, and mitochondrial dysfunction. J. Neurosci. 18, 687-697.

Kim G. W. and Chan P. H. (2001) Oxidative stress and neuronal DNA fragmentation mediate agedependent vulnerability to the mitochondrial toxin, 3-nitropropionic acid, in the mouse striatum. Neurobiol. Dis. 8, 114-126.

Kim-Han J. S., Reichert S. A., Quick K. L., and Dugan L. L. (2001) BMCP1: a mitochondrial uncoupling protein in neurons which regulates mitochondrial function and oxidant production. J. Neurochem. 79, 658-668.

Knapp L. T. and Klann E. (2002) Role of reactive oxygen species in hippocampal long-term potentiation: contributory or inhibitory? J. Neurosci. Res. 70, 1-7.

Kokaia Z., Andsberg G., Martinez-Serrano A., and Lindvall O. (1998) Focal cerebral ischemia in rats induces expression of P75 neurotrophin receptor in resistant striatal cholinergic neurons. Neuroscience 84, 1113-1125.

Korshunov S. S., Skulachev V. P., and Starkov A. A. (1997) High protonic potential actuates a mechanism of production of reactive oxygen species in mitochondria. FEBS Lett. 416, 15-18. 
Korshunov S. S., Korkina O. V., Ruuge E. K., Skulachev V. P., and Starkov A. A. (1998) Fatty acids as natural uncouplers preventing generation of $\mathrm{O}_{2}{ }^{-}$and $\mathrm{H}_{2} \mathrm{O}_{2}$ by mitochondria in the resting state. FEBS Lett. 435, 215-218.

Kowaltowski A. J., Smaili S. S., Russell J. T., and Fiskum G. (2000) Elevation of resting mitochondrial membrane potential of neural cells by cyclosporin A, BAPTA-AM, and bcl-2. Am. J. Physiol. Cell Physiol. 279, C852-C859.

Kowaltowski A. J., Cosso R. G., Campos C. B., and Fiskum G. (2002) Effect of bcl-2 overexpression on mitochondrial structure and function. J. Biol. Chem. 277, 42,802-42,807.

Kristián T. and Siesjö B. K. (1998) Calcium in ischemic cell death. Stroke 29, 705-718.

Krohn A. L., Wahlbrink T., and Prehn J. H. M. (1999) Mitochondrial depolarization is not required for neuronal apoptosis. J. Neurosci. 19, 7394-7404.

Kruman I. I., Bruce-Keller A. J., Bredesen D., Waeg G., and Mattson M. P. (1997) Evidence that 4hydroxynonenal mediates oxidative stress-induced neuronal apoptosis. J. Neurosci. 17, 5089-5100.

Kruman I. I. and Mattson M. P. (1999) Pivotal role of mitochondrial calcium uptake in neural cell apoptosis and necrosis. J. Neurochem. 72, 529-540.

Li B., Nolte L. A., Ju J., et al. (2000) Skeletal muscle respiratory uncoupling prevents diet-induced obesity and insulin resistance in mice. Nat. Med. 6, 1115-1120.

Li L., Prabhakaran K., Shou Y., Borowitz J. L., and Isom G. E. (2002) Oxidative stress and cyclooxygenase-2 induction mediate cyanide-induced apoptosis of cortical cells. Toxicol. Appl. Pharmacol. 185, 55-63.

Lin S. and Huang X. F. (1997) Fasting increases leptin receptor mRNA expression in lean but not obese (ob/ob) mouse brain. Neuroreport 8, 3625-3629.

Liu D., Lu C., Wan R., Auyeung W. W., and Mattson M. P. (2002) Activation of mitochondrial ATPdependent potassium channels protects neurons against ischemia-induced death by a mechanism involving suppression of Bax translocation and cytochrome c release. J. Cereb. Blood Flow Metab. 22, 431-443.

Lynch R. M., Tompkins L. S., Brooks H. L., DunnMeynell A. A., and Levin B. E. (2000) Localization of glucokinase gene expression in the rat brain. Diabetes 49, 693-700.

Mao W., Yu X. X., Zhong A., et al. (1999) UCP4, a novel brain-specific mitochondrial protein that reduces membrane potential in mammalian cells. FEBS Lett. 443, 326-330.
Mark R. J., Pang Z., Geddes J. W., Uchida K., and Mattson M.P. (1997) Amyloid beta-peptide impairs glucose transport in hippocampal and cortical neurons: involvement of membrane lipid peroxidation. J. Neurosci. 17, 1046-1054.

Maswood N., Young J., Tilmont E., et al. (2004) Caloric restriction increases neurotrophic factor levels and attenuates neurochemical and behavioral deficits in a primate model of Parkinson's disease. Proc. Natl. Acad. Sci. USA 101, 18,171-18,176.

Mattiasson G., Shamboo M., Gido G., et al. (2003) Uncoupling protein-2 prevents neuronal death and diminishes brain dysfunction after stroke and brain trauma. Nat. Med. 9, 1062-1068.

Mattson M. P., Barger S. W., Begley J. G., and Mark R. J. (1995) Calcium, free radicals, and excitotoxic neuronal death in primary cell culture. Methods Cell Biol. 46, 187-216.

Mattson M. P. and Liu D. (2002) Energetics and oxidative stress in synaptic plasticity and neurodegenerative disorders. Neuromolecular Med. 2, 215-231.

Mattson M. P. (2003) Gene-diet interactions in brain aging and neurodegenerative disorders. Ann. Intern. Med. 139, 441-444.

Mattson M. P. and Kroemer G. (2003) Mitochondria in cell death: novel targets for neuroprotection and cardioprotection. Trends Mol. Med. 9, 196-205.

Merchenthaler I., Lane M., and Shughrue P. (1999) Distribution of pre-pro-glucagon and glucagonlike peptide-1 receptor messenger RNAs in the rat central nervous system. J. Comp. Neurol. 403, 261-280.

Merry B. J. (2004) Oxidative stress and mitochondrial function with aging - the effects of calorie restriction. Aging Cell 3, 7-12.

Millet L., Vidal H., Andreelli F., et al. (1997) Increased uncoupling protein-2 and -3 mRNA expression during fasting in obese and lean humans. J. Clin. Invest. 100, 2665-2670.

Miwa S. and Brand M. D. (2003) Mitochondrial matrix reactive oxygen species production is very sensitive to mild uncoupling. Biochem. Soc. Trans. 31, 1300-1301.

Mizuno T., Miura-Suzuki T., Yamashita H., and Mori N. (2000) Distinct regulation of brain mitochondrial carrier protein-1 and uncoupling protein-2 genes in the rat brain during cold exposure and aging. Biochem. Biophys. Res. Commun. 278, 691-697.

Murphy A. N. and Fiskum G. (1999) Bcl-2 and Ca(2+)mediated mitochondrial dysfunction in neural cell death. Biochem. Soc. Symp. 66, 33-41. 
Nasr P., Gursahani H. I., Pang Z., et al. (2003) Influence of cytosolic and mitochondrial $\mathrm{Ca} 2+$, ATP, mitochondrial membrane potential, and calpain activity on the mechanism of neuron death induced by 3-nitropropionic acid. J. Neurochem. 43, 89-99.

Negre-Salvayre A., Hirtz C., Carrera G., et al. (1997) A role for uncoupling protein-2 as a regulator of mitochondrial hydrogen peroxide generation. FASEB J. 11, 809-815.

Nicholls D. G. and Locke R. M. (1984) Thermogenic mechanisms in brown fat. Physiol. Rev. 64, 1-64.

Nicholls D. G. and Budd S. L. (1998) Mitochondria and neuronal glutamate excitotoxicity. Biochim. Biophys. Acta 1366, 97-112.

O'Brien J., Wilson I., Orton T., and Pognan F. (2000) Investigation of the alamar blue (resazurin) fluorescent dye for the assessment of mammalian cell cytotoxicity. Eur. J. Biochem. 267, 5421-5426.

Pecqueur C., Couplan E., Bouillaud F., and Ricquier D. (2001) Genetic and physiological analysis of the role of uncoupling proteins in human energy homeostasis. J. Mol. Med. 79, 48-56.

Peng T. I., Jou M. J., Sheu S. S., and Greenamyre J. T. (1998) Visualization of NMDA receptor-induced mitochondrial calcium accumulation in striatal neurons. Exp. Neurol. 149, 1-12.

Pereira C., Santos M. S., and Oliverira C. (1999) Involvement of oxidative stress on the impairment of energy metabolism induced by $A \beta$ peptides on PC12 cells: protection by antioxidants. Neurobiol. Dis. 6, 209-219.

Pisani A., Bonsi P., Bernardi G., and Calabresi P. (2002) Impairment of mitochondrial metabolism differentially affects striatal neuronal subtypes. Neuroreport 13, 641-644.

Poppe M., Reimertz C., Dussmann H., et al. (2001) Dissipation of potassium and proton gradients inhibits mitochondrial hyperpolarization and cytochrome c release during neural apoptosis. J. Neurosci. 21, 4551-4563.

Rea S. and Johnson T. E. (2003) A metabolic model for life span determination in Caenorhabditis elegans. Dev. Cell 5, 197-203.

Richard D., Rivest R., Huang Q., et al. (1998) Distribution of the uncoupling protein 2 mRNA in the mouse brain. J. Comp. Neurol. 397, 549-560.

Rial E. and Nicholls D. G. (1984) The mitochondrial uncoupling protein from guinea-pig brown adipose tissue. Synchronous increase in structural and functional parameters during cold-adaptation. Biochem. J. 222, 685-693.
Rial E., González-Barroso M., Fleury C., et al. (1999) Retinoids activate proton transport by the uncoupling proteins UCP1 and UCP2. EMBO J. 18, 5827-5833.

Richard D., Rivest R., Huang Q., et al. (1998) Distribution of the uncoupling protein 2 mRNA in the mouse brain. J. Comp. Neurol. 397, 549-560.

Roth G. S., Lane M. A., Ingram D. K., et al. (2002) Biomarkers of caloric restriction may predict longevity in humans. Science 297, 811.

Roussel D., Harding M., Runswick M. J., Walker J. E., and Brand M. D. (2002) Does any yeast mitochondrial carrier have a native uncoupling protein function. J. Bioenerg. Biomembr. 34, 165-176.

Samartsev V. N., Mokhova E. N., and Skulachev V. P. (1997) The $\mathrm{pH}$-dependent reciprocal changes in contributions of ADP / ATP antiporter and aspartate/glutamate antiporter to fatty acid-induced uncoupling. FEBS Lett. 412, 179-182.

Sanchis D., Fleury C., Chomiki N., et al. (1998) BMCP1, a novel mitochondrial carrier with high expression in the central nervous system of humans and rodents, and respiration uncoupling activity in recombinant yeast. J. Biol. Chem. 273, 34,611-23,615.

Simpson P. B. (2000) The local control of cytosolic $\mathrm{Ca}^{2+}$ as a propagator of CNS communication-integration of mitochondrial transport mechanisms and cellular responses. J. Bioenerg. Biomembr. 32, 5-13.

Sokolova I. M. and Sokolov E. P. (2005) Evolution of mitochondrial uncoupling protein: novel invertebrate UCP homologues suggest early evolutionary divergence of the UCP family. FEBS Lett. 579, 313-317.

Starkov A. A. (1997) Mild uncoupling of mitochondria. Biosci. Rec. 17, 273-279.

Starkov A. A. and Fiskum G. (2003) Regulation of brain mitochondrial $\mathrm{H}_{2} \mathrm{O}_{2}$ production by membrane potential and $\mathrm{NAD}(\mathrm{P}) \mathrm{H}$ redox state. J. Neurochem. 86, 1101-1107.

Stuart J. A., Harper J. A., Brindle K. M., Jekabsons M. B., and Brand M. D. (2001) A mitochondrial uncoupling artifact can be caused by expression of uncoupling protein 1 in yeast. Biochem. J. 356, 779-789.

Sullivan P. G., Dube C., Dorenbos K., Steward O., and Baram T.Z. (2003) Mitochondrial uncoupling protein-2 contributes crucially to the resistance of immature brain to excitotoxic neuronal death. Ann. Neurol. 53, 711-717.

Vercesi A. E., Bernardes C. F., Hoffmann M. E., Gadelha F. R., and Docampo R. (1991) Digitonin permeabilization does not affect mitochondrial function and allow the determination of the mitochondrial 
potential of Trypanosome cruzi in situ. J. Biol. Chem. 266, 14,431-14,434.

Vianello A., Petrussa E., and Macri F. (1994) ATP / ADP antiporter is involved in uncoupling of plant mitochondria induced by low concentratios of palmitate. FEBS Lett. 349, 407-410.

Vidal-Puig A.J., Grujic D., Zhang C., et al. (2000) Energy metabolism in uncouple protein 3 gene knockout mice. J. Biol. Chem. 275, 16,258-16,266.

Vincent A. M., Olzmann J. A., Brownlee M., Sivitz W. I., and Russell J. W. (2004) Uncoupling proteins prevent glucose-induced neuronal oxidative stress and programmed cell death. Diabetes 53, 726-734.

Weigle D. S., Selfridge L. E., Schwartz M. W., et al. (1998) Elevated free fatty acids induce uncoupling protein 3 expression in muscle: a potential explanation for the effect of fasting. Diabetes 47, 298-302.

Weindruch R. and Sohal R. S. (1997) Seminars in medicine of the Beth Israel Deaconess Medical Center. Caloric intake and aging. NEngl J Med. 337, 986-994.

White M. J., Dicaprio M. J., and Greenberg D. A. (1996) Assessment of neuronal viability with Alamar blue in cortical and granule cell cultures. J. Neurosci. Methods 70, 195-200.

Wieckowski M. R. and Wojtczak L. (1997) Involvement of the dicarboxylate carrier in the protonophoric action of long-chain fatty acids in mitochondria. Biochem. Biophys. Res. Commun. 232, 414-417.

Yang X., Pratley R. E., Tokraks S., Tataranni P. A., and Permana P. A. (2002) UCP5/BMCP1 transcript isoforms in human skeletal muscle: relationship of the short-insert isoform with lipid oxidation and resting metabolic rates. Mol. Genet. Metab. 75, 369-373.

Yang F., He X. P., Russell J., and Lu B. (2003) $\mathrm{Ca}^{2+}$ influxindependent synaptic potentiation mediated by mitochondrial $\mathrm{Na}(+)-\mathrm{Ca}^{2+}$ exchanger and protein kinase C. J. Cell Biol. 163, 511-523.

Yu Z. F. and Mattson M. P. (1999) Dietary restriction and 2-deoxyglucose administration reduce focal ischemic brain damage and improve behavioral outcome: evidence for a preconditioning mechanism. J. Neurosci. Res. 57, 830-839.

Yu X. X., Lewin D. A., Zhong A., et al. (2001) overexpression of the human 2-oxoglutarate carrier lowers mitochondrial membrane potential in HEK-293 cells: contrast with the unique cold-induced mitochondrial carrier CG1-69. Biochem. J. 353, 369-375.

Yu X. X., Mao W., Zhong A., et al. (2000) Characterization of novel UCP5/BMCP1 isoforms and differential regulation of UCP 4 and UCP5 expression through dietary or temperature manipulation. FASEB J. 14, 1611-1618.

Zhang C., Baffy G., Perret P., et al. (2001) Uncoupling protein-2 negatively regulates insulin secretion and is a major link between obesity, $\beta$ cell dysfunction, and type 2 diabetes. Cell 105, 745-755.

Zorumski C. F. and Izumi Y. (1998) Modulation of LTP induction by NMDA receptor activation and nitric oxide release. Prog. Brain Res. 118, 173-182. 